\title{
Uncertainty Analysis of WDN Pipes Repair and Replacement Optimal Instruction Using EPANET Simulation Model and Fuzzy Cut Approach Combination
}

\section{Seyed Mehran Jafari}

Gorgan University of Agricultural Sciences and Natural Resources

Abdol Reza Zahiri

Gorgan University of Agricultural Sciences and Natural Resources

Omid Bozorg Hadad

University of Tehran

Mahmoud Mohammad Rezapour Tabari ( $D$ mrtabari57@gmail.com )

University of Mazandaran https://orcid.org/0000-0002-4837-5026

\section{Research Article}

Keywords: Uncertainty, Fuzzy a-cut method, Pipe repair and replacement, Water distribution network, Reliability index, Hydraulic simulation

Posted Date: November 3rd, 2021

DOI: https://doi.org/10.21203/rs.3.rs-726002/v1

License: (9) This work is licensed under a Creative Commons Attribution 4.0 International License.

Read Full License 


\title{
Uncertainty analysis of WDN pipes repair and replacement optimal instruction using EPANET simulation model and fuzzy cut approach combination
}

\author{
S. M. Jafari ${ }^{1}$, A. R. Zahiri ${ }^{2}$, O. Bozorg Hadad ${ }^{3}$, M. Mohammad Rezapour Tabari ${ }^{* *}$ \\ ${ }^{1}$ Ph.D. Graduate, Dept. of Water Engineering, University of Gorgan Agriculture Sciences and Natural Resources \\ ${ }^{2}$ Associate Professor, Dept. of Water Engineering, University of Gorgan Agriculture Sciences and Natural \\ Resources, Iran, E-mail: zahiri.areza@gmail.com \\ ${ }^{3}$ Professor Dept. of Water Engineering, University of Tehran,Iran \\ ${ }^{4}$ Associate Prof., Department of Civil Engineering, Faculty of Technology and Engineering, University of \\ Mazandaran, Mazandaran, Iran, E-mail: mrtabari@umz.ac.ir (Corresponding Author) \\ ${ }^{4}$ Center of Excellence in Risk Management and Natural Hazards, Isfahan University and Technology, Isfahan, \\ Iran
}

\begin{abstract}
Optimization of the initial design or pipes repair and replacement instructions of water distribution network during operation period is based on the crisp values of the input variables. Some input variables such as node demand, pipe roughness coefficient and reservoir water level have the uncertain nature. Changing the input parameters values during operation period, due to uncertainty, changes the water distribution network behavior and performance compared to the crisp input parameters values. Recognition and analyzing these behaviors are very important to make the right decision to deal with their consequences and reduce the water distribution network problems, during operation period. In this research, the water distribution network nodes pressure uncertainty due to the pipe's roughness coefficient and the nodes demand uncertainty as input parameters, is analyzed after the implementation of the optimal pipes repair and replacement instruction. For the purpose, a combination of simulation model (EPANET) and fuzzy $\alpha$-cut approach is used. Fuzzy membership functions of the input and output variables are selected as triangular type and the membership functions values, after normalization, were in the range of zero and one . The extreme values combinations of two uncertain input variables, at each uncertainty level, in the form of four scenarios, were considered as the input fuzzy set of the simulation model. Between the research scenarios, the second scenario, which is the combination of the minimum pipe roughness coefficient and the maximum demand, is known as the critical scenario. The research results show that in the critical scenario, at the highest uncertainty level, the water
\end{abstract}


distribution network reliability index is very low and about 30 to $40 \%$ due to lack of required pressure of the most nodes. At the uncertainty lower levels, the reliability index rises above $75 \%$, which is relatively acceptable. In the first and fourth scenarios, the network reliability index is always more than $72 \%$. In the third scenario, the network reliability index, at all uncertainty levels, is always more than $90 \%$.

\section{Keywords}

Uncertainty, Fuzzy $\alpha$-cut method, Pipe repair and replacement, Water distribution network, Reliability index, Hydraulic simulation.

\section{Introduction}

Hydraulic simulations of water distribution networks (WDN) are always performed by simplified models of a real network based on the crisp and known values of input variables. Values of some input variables such as nodes demand, pipes roughness coefficient, pipe length and diameter and reservoir water surface level, etc., fluctuate during the operation period. This means that a fixed value cannot be considered for these parameters during the WDN operation period. These variables are called uncertain variables. Sources of the uncertainties are divided into three categories: 1) measurement tools, 2) lack of knowledge, and 3) network simplification. The first category includes the pipes length and diameter, the pumps specifications and the water surface level of the tanks (Ivetić 1996; Kapelan et. al. 2005). In the second and third categories, variables such as pipe roughness coefficient, pressure head loss, and nodes demand are noteworthy. Although measurement or measurement criteria may be wrong, using better measurement tools can prevent errors and mistakes of them. Therefore, the most uncertainties belong to the second and third categories, is lack of information about parameters and WDN simplification.

Uncertain input parameters such as pipe roughness coefficient and node demand in the simulation and optimization process of WDN, cause uncertainty in the WDN output parameters such as pipes velocity and flow rate and nodes pressure and demand. The WDN designed based on the crisp values of input parameters, will always have unpredictable behavior and different hydraulic performance during operation period. Therefore, considering the input parameters uncertainty in designing and performance analyzing of WDN is very important. Input parameters uncertainties of WDN simulation models can be expressed and investigated in two ways. The first approach involves the WDN design or optimization by considering the input parameters uncertainties. In the approach, uncertain input parameters are quantified using different methods and entered into the 
WDN simulation or optimization process. In the second approach, which is called WDN uncertainty analysis, the network is first simulated and optimized with crisp values. In the next step, after the input parameters quantifying, the effect of the input parameters uncertainty on the simulation and optimization models output and hydraulic performance of the WDN is investigated and analyzed. There are various methods to quantify and analyze the input variables uncertainty of the simulation and optimization models, such as Monte Carlo simulation (MCS), first-order second momentum (FOSM), first-order second-order momentum (MFOSM), first-order second momentum mean, first order reliability method (FORM), fuzzy and entropy theory. Monte Carlo simulation (MCS) and fuzzy methods are the most used among other methods. The Monte Carlo simulation (MCS) method has widely used by various researchers for quantify and analysis of WDNs. This method is based on probabilities and a large number of modeling calculations for statistical estimation of input parameters. In the method, a lot of information to define the probabilistic density function (PDF) of the input parameters as well as the high execution time even on fast computers is needed. It is not possible to determine the appropriate probability distribution function for the observed data in the absence of information (Seifollahi-Aghmiuni et al. 2011, 2013a, 2013b; Bao and Mays 1990; Xu and Gouter 1999). The fuzzy method is another tool to analyze input variables uncertainty in case of lack of uncertain variables information. In the method, an uncertain variable is considered as an independent fuzzy parameter and a membership function is assigned to it. The type of membership function is selected based on the available information, knowledge and judgment of the designer. Based on the proposed approach, this method is used for fuzzy uncertainty analysis or fuzzy design. In the fuzzy design approach, uncertain input variables are entered into the optimization process as a fuzzy set and then the WDN is designed with the least cost of the WDN's equipment construction such as pipes, pumps, valves, tanks, etc. and the highest performance during the operation period (Bozorg-Haddad et al. 2017; Donger and Gupta 2017; Shibu and Reddy 2012; Farmani et al. 2005a, 2005b; Dridi et al. 2009; Amirabdollahian et al. 2011; Mosavian and Lence 2018). In the fuzzy uncertainty analysis, the extraction of output parameters membership functions such as nodes demand and pressure and pipes flow velocity and their analysis is considered (Sabzkouhi and Haghighi 2016; Branisavljevic and Ivetic 2006; Revelli and Ridolfi 2002; Spiliotis and Tsakiris 2012; Shibu and Reddy 2011; Gupta and Bhave 2007; Moosavian and Lence 2018; Geranmehr et al. 2019; Gupta et al. 2014). 
Revelli and Ridolfi (2002) performed the uncertainty analysis of WDN based on the uncertain input variables include the nodes demand and pipes roughness coefficient. They investigated the effect of input uncertainties on output variables including pipes flow rate and nodes pressure. They estimate the extreme values (i.e., Maximum and minimum) of the output variables using the $\alpha$-cut fuzzy optimization method and second quadratic programming (SQP). In this method, for each node, the optimization is repeated for different $\alpha$-cut between zero and one. This significantly increased the computation time. They applied this method for two-loop and hypothetical benchmark WDNs. In order to reduce the computational time of fuzzy hydraulic analysis, Gupta and Bhave (2007) proposed a direct method to estimate the nodes pressure and pipes flow rate extreme values. In this method, it is not necessary to repeat the optimization of each $\alpha$-cut, but the hydraulic analysis is performed based on the most likely value of the pipe roughness coefficient and nodes demand. Seifollahi-Aghmiuni and Bozog-Haddad (2011, 2013b) investigated the effect of pipe roughness coefficient and nodes demand uncertainties (separately) on the WDN hydraulic performance during operation period. In this research, uncertainty analysis is performed using probabilistic series of pipes roughness coefficient and nodes demand and MCS method.

Following the previous researches, Moosavian and Lence (2018) proposed an approximate method to obtain the fuzzy membership functions of the WDN's output parameters. In the research, they used the analytical solution model that presented by Gupta and Bhave (2007). Uncertain input parameters of the research include pipes roughness coefficient and nodes demand. In this method, for only one input fuzzy parameter, WDN analysis requires only two simulation runs to find the output extreme values. If there are two uncertain input variables (such as pipe roughness coefficient and node demand), two matrices should be constructed based on network information. Therefore, the fuzzy analytical method, developed in this research, reduces the network analysis time because, for each additional node, the computations only be double, unlike the previous studies methods, which computations will significantly increase by increasing the WDN size. WDNs pipes because of pipes aging and deterioration and WDN development need due to population growth, need replacement and repair operations during the operation period. Selecting the most suitable pipes replacement or repair operation and diameter are the most important challenges for the WDNs operational management because they affect the WDN's cost and hydraulic performance during operational period. The solution to deal with the important challenge is providing optimal pipes repair and replacement instructions using multi-objective optimization 
approaches, which have been studied by various researchers (Jafari 2020; Maier et al. 2003; Prasad and Park 2004; Kapelan et al. 2005; Vamvakeridou-Lyroudia et al. 2005; Dandy and Engelhardt 2006; Dridi et al. 2008, 2009; Fu et al. 2011; Wang et al. 2015; Baños et al. 2011; Shafiqul et al. 2014; Shirzad and Tabesh 2016; Liu et al. 2017; Bozorg-Haddad et al. 2017; Dini and Tabesh 2018; Gheisi and Nasera 2015).

Optimal pipes repair and replacement instruction is determined based on the crisp input parameters values such as pipes roughness coefficient and nodes demand. Occurrence of the uncertain input values after optimal instructions implementation, affects the WDN performance during the operation period, so that it may reduce WDN's performance.

A review of previous researches shows that using the fuzzy method was limited to calibration, initial design, and analysis of existing networks. Fuzzy uncertainty analysis of pipes replacement and repair optimal instruction has not been considered by previous researchers. Therefore, as the main goal and innovation of the present study, the uncertainty analysis of a real WDN studied after implementation the optimal pipes repair and replacement instruction (Jafari 2020), with two uncertain input variables including the pipes roughness coefficient and nodes demand and using the $\alpha$-cut fuzzy method. The present study approach was applied to the Goragn city WDN.

\section{Research Method}

\subsection{Uncertainty Analysis Approach}

The present study goal is uncertainty analysis of the optimal pipe repair and replacement instructions with two uncertain input variables, including the pipes roughness coefficient and nodes demand, for 5-year operational management. Therefore, the research approach is defined as a combination of fuzzy and simulations models. The nodes pressure during the project planning period was considered as the uncertain output variable in this research. The uncertainty analysis structure of this research is shown in Fig.1. 


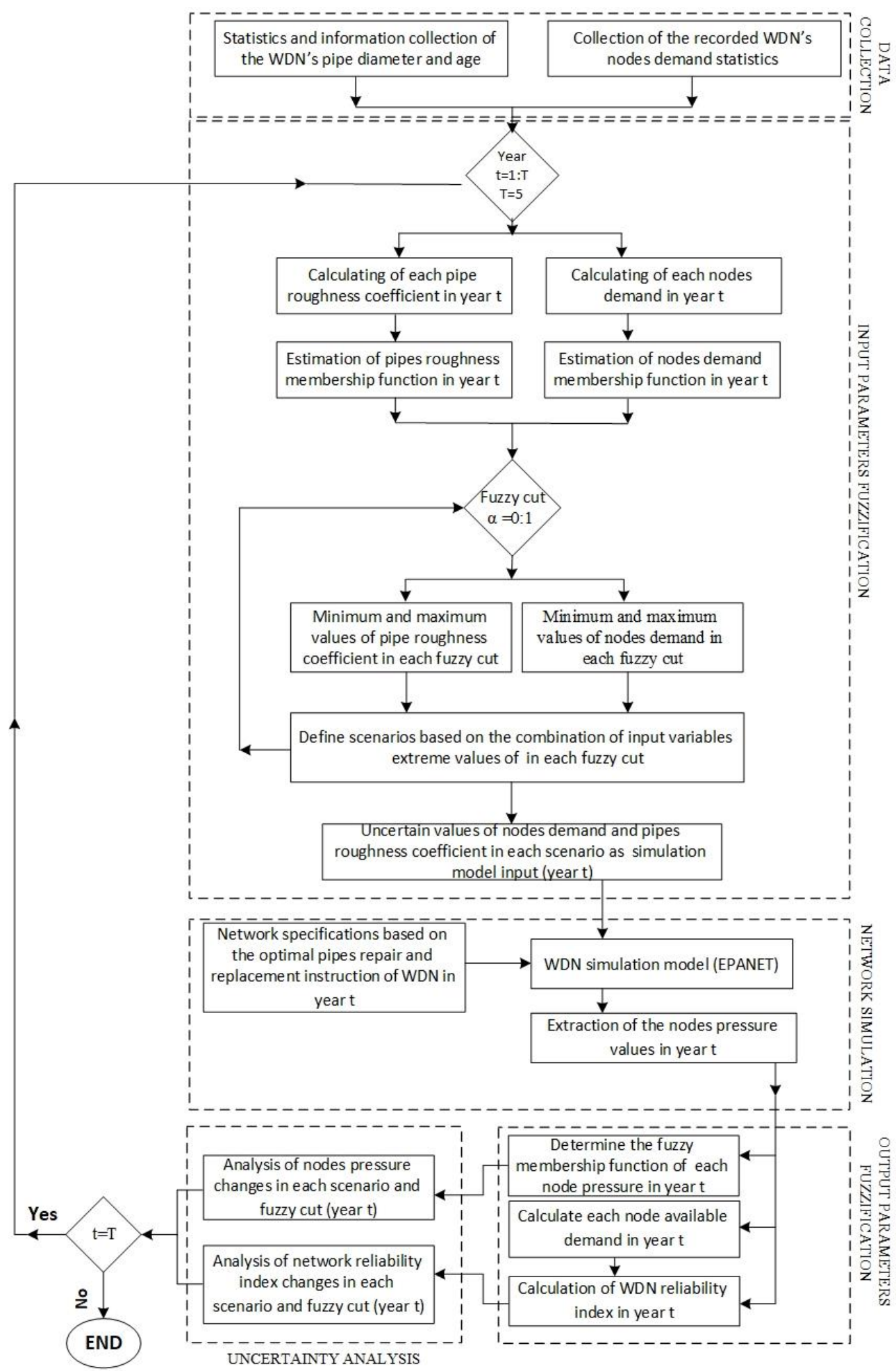

Fig. 1 Structure of the uncertainty analysis approach of the optimal pipes repair and replacement instruction 
The uncertainty analysis approach of the present study has the following steps:

a) Collecting and refining information: At this stage, statistics and information of the WDN's nodes demand, as well as the existing pipes diameter and age collect and refine in order to predict the nodes demand values and calculate the pipes roughness coefficients during the planning period.

b) Uncertain input variables fuzzification: At this stage, the uncertain input variables is quantified using the fuzzy method and used as the input values of the simulation model in the next step. For the purpose, the variation interval of two uncertain input variables (node demand and pipe roughness coefficient), is determined based on the previous stage data, and then their fuzzy membership functions are extracted. Extreme values (minimum and maximum) of each uncertain input variable are extracted from their membership functions, in five different fuzzy cuts. Four scenarios obtain based on the extreme values combinations of the two uncertain input variables, for each fuzzy cut and are used as the input of the WDN's simulation model.

c) WDN hydraulic simulation: At this stage, the optimal pipes repair and replacement instruction during the project planning period were applied to the existing WDN. Then, the WDN hydraulic simulation is performed based on the nodes demand and pipe roughness coefficient values of each scenario during the planning period, using the EPANET model. Then, the WDN's nodes pressure values in each year and fuzzy cut were extracted as an uncertain output variable.

d) Uncertain output variable fuzzification: The membership functions of the nodes pressure (as an uncertain output variable) obtain using the node pressure values in each year and each fuzzy cut.

e) Uncertainty analysis: In this stage, the effect of nodes demand and pipes roughness coefficient uncertainty on the nodes pressure and WDN's hydraulic performance present as the WDN's uncertainty analysis.

\subsection{Case study}

The present study area is the city of Gorgan with a longitude of 26.54 and a latitude of 36.50. in the north of Iran. The pipes failure statistics of Gorgan WDN show that the pipes failure number 
in the WDN is relatively high due to the WDN aging which caused several operational problems (Jafari et al. 2020, 2021).

\subsection{Optimal pipes repair and replacement instruction}

In the research uncertainty analysis approach, it is necessary to prepare optimal pipe repair and replacement instruction during the project planning period. Jafari (2020) has developed a new approach to provide WDN's optimal pipe repair and replacement instruction. The proposed approach is a combination of WDN hydraulic simulation models (EPANET), hybrid model to predict the pipes failure rate, multi-objective optimization model (NSGA-II) to calculate the optimal solution set and multi-decision-making model to for select the best optimal solution. In the above study, the annual nodes demand values during the project planning period were predicted using the relationship presented by Taebi and Chamani (2005) and based on the nodes demand of in the base year and the geometric population growth rate. The pipes roughness coefficient of WDN during the project planning period was estimated using the relationship provided by Sharp and Walski (1988). One of the research approach innovation was using a hybrid model (with combination of six statistical and intelligent models) to predict the WDN pipes failure rate. Pipe failure rates were used to calculate the pipes repair cost in the optimization process (Jafari et al. 2020).

In the multi-objective optimization problem of the research, the WDN's pipes diameter and the operation type (repair or replacement) in the project planning period have considered as decision variables. Objective functions of the multi-objective optimization problem include minimizing the pipes repair and replacement cost and maximizing the WDN hydraulic performance. The mathematical form of the optimization objective functions is as Eq. (1).

Satisfy : $\left(\operatorname{Min}(\right.$ Cost $\left.), \operatorname{Max}\left(\operatorname{Re}_{\text {sys }}\right)\right)$

where, Cost is the total cost of pipes repair and replacement in the planning period (Rials) and $\mathrm{Re}_{\text {sys }}$ is the performance index of the WDN during the planning period.

The reliability index $\left(\operatorname{Re}_{\text {sys }}\right)$ is as the Eq. (2).

$\mathrm{Re}_{\text {sys }}=\left(\mathrm{WSI}_{\text {sys }} \times \mathrm{MEI}_{\text {sys }}\right)^{1 / 2}$

wherer, $\operatorname{Re}_{\text {sys }}$ is the total system reliability index, $\mathrm{WSI}_{\text {sys }}$ is the total system water supply index and $\mathrm{MEI}_{\text {sys }}$ is the modified delivery uniformity index . In the new reliability index $\left(\mathrm{Re}_{\mathrm{sys}}\right)$, the nodes deficit is considered as the node's importance, which has improved the water supply and delivery 
uniformity indices. The NSGA-II algorithm has used to solve the WDN's multi-objective optimization problem. Selected optimal scenario provides the optimal pipes diameter and required operation type (including repair or replacement) during the project planning period. An example of this instruction for pipes No.1 to 5 is presented in Table 2.

Table 2 Example of the pipes optimal repair and replacement instruction

\begin{tabular}{|c|c|c|c|c|c|}
\hline \multirow{2}{*}{$\begin{array}{c}\text { No. of } \\
\text { pipe/Year }\end{array}$} & \multicolumn{5}{|c|}{ Type of operation } \\
\cline { 2 - 6 } & 1 & 2 & 3 & 4 & 5 \\
\hline 1 & N-replace & Repair & Repair & Repair & Repair \\
\hline 2 & Repair & Replace & Repair & Repair & Repair \\
\hline 3 & Repair & Replace & Repair & Repair & Repair \\
\hline 4 & Repair & Repair & Repair & Repair & Repair \\
\hline 5 & Repair & N- replace & Repair & Repair & Repair \\
\hline
\end{tabular}

\begin{tabular}{|c|c|c|c|c|c|}
\hline \multicolumn{5}{|c|}{ Diameter (mm) } \\
\hline Exist & 1 & 2 & 3 & 4 & 5 \\
\hline 150 & 250 & 250 & 250 & 250 & 250 \\
\hline 150 & 150 & 150 & 150 & 150 & 150 \\
\hline 150 & 150 & 250 & 250 & 250 & 250 \\
\hline 150 & 150 & 150 & 150 & 150 & 150 \\
\hline 150 & 150 & 150 & 150 & 150 & 150 \\
\hline
\end{tabular}

\subsection{Fuzzy membership functions of uncertainty input variables}

Definition of fuzzy membership function or fuzzy set of uncertain input variables is necessary to uncertainty analyze. The fuzzy set does not represent probabilities, but the possible values space with emphasis on the most probable value. In other words, the membership function only states information about how much a variable belongs to the set, regardless of the value's possible probability. The normalized membership function values are between zero and one, which values close to one indicating more belonging to the fuzzy set, and vice versa. The input fuzzy set can be formed based on measured or experimental data or a combination of these two data. In this study, uncertain variables include the nodes demand and the pipes roughness coefficient, whose membership functions are defined using measurement and experimental data.

2.4.1 Noes demand fuzzy membership function: In order to determine the fuzzy membership functions of the WDN's nodes, it is necessary to determine the definite nodes demand in each year of the project planning period. In this research, the relationship presented by Taebi and Chamani (2005) was used (Eq. (3)).

$\mathrm{Q}(\mathrm{t})=\mathrm{e}^{\left(\ln \left(\mathrm{Q}_{\mathrm{o}}\right)+\mathrm{K}_{\mathrm{g}} \cdot \mathrm{t}\right)}$

where, $\mathrm{Q}(\mathrm{t})$ is the node demand in year $\mathrm{t}\left(\mathrm{m}^{3} / \mathrm{hr}\right), \mathrm{Q}_{\mathrm{o}}$ is the node demand in base year $\left(\mathrm{m}^{3} / \mathrm{hr}\right)$ and $K_{g}$ is the geometric population growth rate during period t year $\left(\mathrm{m}^{3} / \mathrm{hr} /\right.$ year$)$. 
The WDN's nodes demand uncertainty can be quantified using trapezoidal or triangular membership functions (Dongre and Gupta 2017). In the triangular membership function, the most probable value of the nodes demand is only the crisp value $\left(q^{\text {crisp }}\right)$, while in the trapezoidal membership function, the most probable values of the nodes demand are in an interval between the minimum and maximum demand values. Various researchers such as Revelli and Ridolfi 2002; Maskey et al. 2004; Nemanja 2006; Dongre and Gupta 2017; Geranmehr et al. 2019 have considered triangular membership functions for the nodes demand. In this research, according to the observed data of the studied WDN's nodes demand, the triangular membership function used to quantify the WDN's nodes demand. The triangular membership function of the WDN's nodes demand is in the form of Eq. (4) (Geranmehr M. et al. 2019).

$\mu\left(q_{i}\right)=\left\{\begin{array}{cc}o & q_{i} \leq q_{i}^{\text {min }} \\ \frac{q_{i}-q_{i}^{\text {min }}}{q_{i}^{\text {crisp }}-q_{i}^{\text {min }}} & q_{i}^{\text {min }} \leq q_{i} \leq q_{i}^{\text {crisp }} \\ \frac{q_{i}^{\text {max }}-q_{i}}{q_{i}^{\text {max }}-q_{i}^{\text {crisp }}} & q_{i}^{\text {crisp }} \leq q_{i} \leq q_{i}^{\text {max }} \\ o & q_{i} \geq q_{i}^{\text {max }}\end{array}\right.$

where, $\mu\left(q_{i}\right)$ is the fuzzy membership function of node $\mathrm{i}, q_{i}^{\text {crisp }}$ is the crisp demand value of node $\mathrm{i}$ which equal to the annual demand value, $q_{i}^{\max }$ and $q_{i}^{\text {min }}$ are maximum and minimum node demand, respectively. Fig. 2 shows the triangular membership function of the studied WDN's nodes demand based on Eq. (3).



Nodal demand

Fig. 2 Triangular fuzzy membership function of the WDN's nodes demand

The observed nodes demand data of the studied WDN were used to determine the crisp, minimum and maximum values of nodes demand in Eq. (4). For this purpose, the WDN's nodes demand of 
the 4-year statistical period is used. Survey the observed nodes demand data shows that the minimum demand $\left(q_{i}^{\min }\right)$ and the maximum demand $\left(q_{i}^{\max }\right)$ of each node are respectively about $15 \%$ lower and $20 \%$ higher than the required demand or crisp demand $\left(q_{i}^{\text {crisp }}\right)$ of that node. Therefore, using the minimum, maximum and crisp values of each node, the triangular membership function of the node was extracted.

\subsubsection{Membership function of the pipe's roughness coefficient}

Roughness coefficient values of new pipes at the time of installation equal to the values provided by the pipe factory. This value is different for pipes with different materials and diameters. Pipe roughness coefficient in year t, after pipe installation is calculated by Sharp and Walski (1988) relationship (Eq. (5)).

$C_{j}(t)=18-37.2 \log \left(\frac{e+t . a}{D_{j}}\right)$

where, $C_{j}(t)$ is the Heyzen -Williams coefficient in year $\mathrm{t}, \mathrm{D}_{j}$ is pipe diameter $(\mathrm{mm}), j$ is pipe number index, $e$ pipe initial roughness high $(\mathrm{m}), a$ is pipes roughness growth rate.

Due to the lack of access to pipes roughness coefficient changes statistics, the fuzzy membership function of the pipes roughness coefficient in this research is selected as triangular (Branisavljevic and Ivetic 2006; Revelli and Ridolfi 2002; Shibu and Reddy 2011; Gupta and Bhave 2007; Sabzkouhi and Haghighi 2016; Spiliotis and Tsakiris 2012; Gupta et al. 2014; Moosavian and Lence 2018; Geranmehr et al. 2019). The triangular fuzzy membership function of the pipe roughness coefficient determined by Geranmehr et al. (2019) relationship (Eq. (6)).

$$
\mu\left(C_{j}\right)=\left\{\begin{array}{cc}
o & C_{j} \leq C_{j}^{\text {min }} \\
\frac{C_{j}-C_{j}^{\text {min }}}{C_{j}^{\text {crisp }}-C_{j}^{\text {min }}} & C_{j}^{\text {min }} \leq C_{j} \leq C_{j}^{\text {crisp }} \\
\frac{C_{j}^{\text {max }}-C_{j}}{C_{j}^{\text {max }}-C_{j}^{\text {crisp }}} & C_{j}^{\text {crisp }} \leq C_{j} \leq C_{j}^{\max } \\
o & C_{j} \geq C_{j}^{\max }
\end{array}\right.
$$

where, $\mu\left(C_{j}\right)$ is roughness coefficient fuzzy membership function of pipe $\mathrm{j}, C_{j}^{\text {crisp }}$ is crisp roughness coefficient of pipe $\mathrm{j}$ which equals to design roughness coefficient, $C_{j}^{\max }$ and $C_{j}^{\text {min }}$ are maximum and minimum pipe roughness coefficient, respectively, which is not same for all pipes but for each pipe is according to the pipe age. The crisp value of the roughness coefficient $\left(C_{j}^{c r i s p}\right)$ 
is calculated based on the pipe age by Eq. (5). According to Eq. (6), the triangular fuzzy membership function of the pipe's roughness coefficient is shown in Fig. 3.

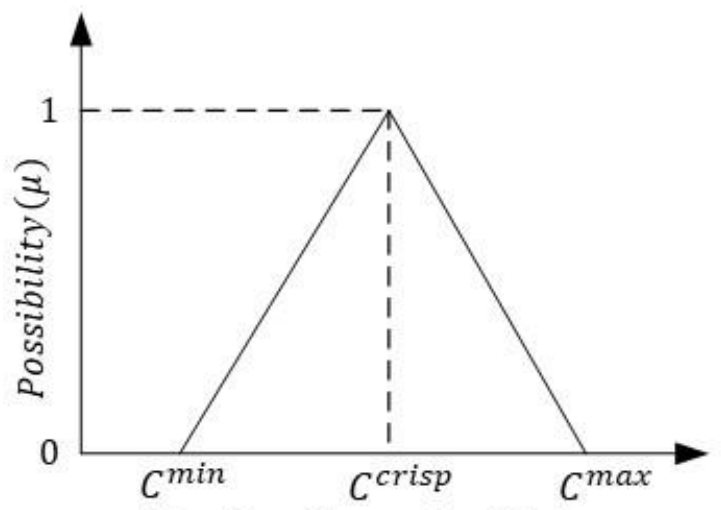

Pipe Roughness Coefficient

Fig. 3 Fuzzy membership function of pipe roughness coefficient

2.4.3 Fuzzy $\boldsymbol{\alpha}$-cut: A fuzzy set that contains all values with membership function $\alpha \in[0,1]$ is called the fuzzy $\alpha$-cut of the membership function (Abeb at al. 2000). If the fuzzy membership function of a variable $\mathrm{A}$ is normalized so that it changes between zero and one, the range changes of the variable $\mathrm{A}$, or in other words the $\alpha$-cut distance, is expressed as Eq. (7) (Branisavljevic \& Ivetic 2006).

$\left[A^{\text {crisp }}\left(\alpha+\frac{k_{1}}{1-k_{1}}\right)\left(1-k_{1}\right), A^{\text {crisp }}\left(\frac{k_{2}}{k_{2}-1}-\alpha\right)\left(k_{2}-1\right)\right]$

$k_{1}=\frac{A^{\text {min }}}{A^{\text {crisp }}}$

$k_{2}=\frac{A^{\max }}{A^{\text {crisp }}}$

where, $A^{\text {crisp }}, A^{\text {min }}$ and $A^{\max }$ are crisp, minimum and maximum value of variable A, respectively. The values of $k_{1}$ for the node demand and the pipe roughness coefficient are 0.85 and 0.9 , respectively, and the values of $k_{2}$ for the node demand and the pipe roughness coefficient are 1.2 and 1.1, respectively. Therefore, Eq. (10)-(13) are used to calculate the limit values (minimum and maximum) of each variable for the desired fuzzy $\alpha$-cut .

$q_{i}^{\min }(\alpha)=q_{i}^{c r i s p}(\alpha)[0.15 \alpha+0.85]$

$q_{i}^{\max }(\alpha)=q_{i}^{\text {crisp }}(\alpha)[1.2-0.2 \alpha]$

$C_{j}^{\text {min }}(\alpha)=C_{j}^{\text {crisp }}(\alpha)[0.2 \alpha+0.8]$ 
$C_{j}^{\max }(\alpha)=C_{j}^{\text {crisp }}(\alpha)[1.1-0.1 \alpha]$

where, $q_{i}^{\min }(\alpha)$ and $q_{i}^{\max }(\alpha)$ are minimum and maximum demand values of node i for fuzzy $\alpha$-cut respectively, $C_{j}^{\min }(\alpha)$ and $C_{j}^{\max }(\alpha)$ are minimum and maximum roughness coefficient values of pipe $\mathrm{j}$, respectively. To determine the fuzzy membership function of the output variable, it is necessary to derive the limit values of each input variables for different fuzzy $\alpha$-cuts. In order to reduce the study computational volume, due to the large size of the real WDN, only zero, 0.2, 0.4, 0.6 and 0.8 fuzzy $\alpha$-cuts are considered for each membership functions of the input variables. Two limit values (maximum and minimum) are obtained for each fuzzy $\alpha$-cut, using each input variable membership function. Therefore, four scenarios are defined based on the combination of the limit values of the uncertain input variables including nodes demand and the pipes roughness coefficient for each fuzzy $\alpha$-cut. The four scenarios in each fuzzy $\alpha$-cut are presented in Table 3 . fuzzy membership function of output variable obtains using these scenarios, which are discussed in the next section.

Table 3 Four scenarios used in each fuzzy $\alpha$-cut

\begin{tabular}{|c|c|c|c|c|}
\hline $\begin{array}{c}\text { Scenario } \\
\text { name }\end{array}$ & $S 1$ & $S 2$ & $S 3$ & $S 4$ \\
\hline Characteristic & $C_{j}^{\min }(\alpha) \& q_{i}^{\min }(\alpha)$ & $C_{j}^{\min }(\alpha) \& q_{i}^{\max }(\alpha)$ & $C_{j}^{\max }(\alpha) \& q_{i}^{\min }(\alpha)$ & $C_{j}^{\max }(\alpha) \& q_{i}^{\max }(\alpha)$ \\
\hline
\end{tabular}

\subsection{Fuzzification of uncertain output variable}

The next step in the uncertainty analysis approach is to determine the membership functions of the WDN's output variables. Network output variables are variables that represent the WDN hydraulic performance alone or in combination with other variables. Nodes available pressure and demand, pipes velocity and flow rate are examples of WDN's output variables that are affected by input variables changes such as nodes demand, pipes roughness coefficient and reservoirs water levels. Membership functions of output variables indicate these variables behavior due to the input variables changes. In the research approach, in order to determine the output fuzzy set, first different levels of the input variables fuzzy $\alpha$-cut are extracted and then the output variable membership function obtain by performing hydraulic simulation on the optimal instruction of WDN for different input variables values. 


\subsubsection{Fuzzification of output variables}

In fuzzy uncertainty analysis method, systems are divided into two categories including: 1) uniform and 2) non-uniform. In uniform systems, the limit values of the input variables lead to the limit values of the output variables. Therefore, fuzzy uncertainty analysis can be done by all limit values combinations of input variables (Maskey et al. 2004; Revelli and Ridolfi 2002; Branisavljevic and Ivetic 2006; Gupta and Bhave 2007). On the other hand, the uncertainty analysis of non-uniform systems is similar to solving an optimization problem in which the minimum and maximum output variables are considered as the optimization objective functions (Spiliotis and Tsakiris 2012; Haghighi and Asl 2014; Sabzkouhi and Haghighi 2016). Therefore, the first step for determining the fuzzy membership function of the WDN's output variables is to determine whether the output variables are uniform or non-uniform. The most important factor to evaluate the WDN's performance is supplying the required demand of consumers, which is a function of the nodes pressure. Investigation of the pressure values change versus the input variables change shows that the nodes pressure changes are uniform (Moosavian and Lence 2018; Branisavljevic and Ivetic 2006; Geranmehr et al. 2019; Braun et al. 2020). Therefore, the limit values and fuzzy membership function of the WDN's node pressure, as the output variable, obtain using the limit values of the uncertain input variables as the WDN simulation model inputs. Other reasons for using the WDN simulation model on the optimal instruction of WDN instead of direct extraction of output parameter uncertainty based on optimization approach are to reduce the computational volume and thus the execution time duration, reduce the number of executions and no need to use the high computational processing power computers.

Table 4 shows the comparison of computation volume, time duration, and computer specifications required for the two optimization and simulation based on optimal instruction of WDN methods in order to investigation of uncertainty analysis in this study. The multi-objective optimization model proposed by Jafari (2020) has 200 initial populations and 150 iteration (as a stop condition) which each simulation model run duration is about 5 seconds.

Table 4 Comparison of computation volume, time duration, and required computer specifications 


\begin{tabular}{|c|c|c|c|}
\hline Method & $\begin{array}{c}\text { No. of } \\
\text { implementation }\end{array}$ & $\begin{array}{c}\text { Consumption time } \\
\text { (hr) }\end{array}$ & Computer properties \\
\hline Optimization & $6 \times 10^{5}$ & 834 & CPU-8cor, RAM-16Gb and HDD-100Gb \\
\hline $\begin{array}{c}\text { Simulation based on } \\
\text { optimal instruction }\end{array}$ & 20 & 0.027 & CPU-2cor, RAM-8Gb and HDD-50Gb \\
\hline
\end{tabular}

In this study, the nodes pressure of the studied WDN considered as the output variable. The node pressure is a uniform variable, so in order to determine its limit values and membership function, the WDN hydraulic simulation is don using EPANET model and based on limit values combination of the uncertain input variables. According to Table 3, the limit values combination number of pipes roughness coefficient and nodes demand for each fuzzy $\alpha$-cut is 4 , so 20 simulations are performed for 5 different fuzzy $\alpha$-cuts. Therefore, by performing the above simulations, 20 different pressure values are obtained for each node.

\subsubsection{WDN hydraulic simulation}

EPANET can perform WDN hydraulic simulation in case of pressure change due to the WDN performance change, pipe failure and components leakage (Dridi et al. 2005; Bozorg-Haddad et al. 2017; Scholten et al. 2014). In addition, the possibility of establishing a connection between the EPANET program and the MATLAB programming environment is one of the program advantages to WDN simulation. Therefore, in this research, EPANET program is used as the WDN hydraulic simulation tool. In order to connect the EPANET program to the MATLAB program environment, a MATLAB code is developed, which allows to enter the required input information as well as call the hydraulic simulation results by accessing the EPANET program library.

\section{Results and discussion}

\subsection{Fuzzy membership function of uncertain input variables}

The nodes demand and the pipes roughness coefficient considered as an uncertain input variable of the studied WDN. The fuzzy membership function of these variables is triangular and determined based on Eq. (3) and Eq. (5). Due to the large number of the WDN's nodes and pipes, the fuzzy membership functions of some nodes demand and pipes roughness coefficient are presented as examples, in Figures 4 to 7. 


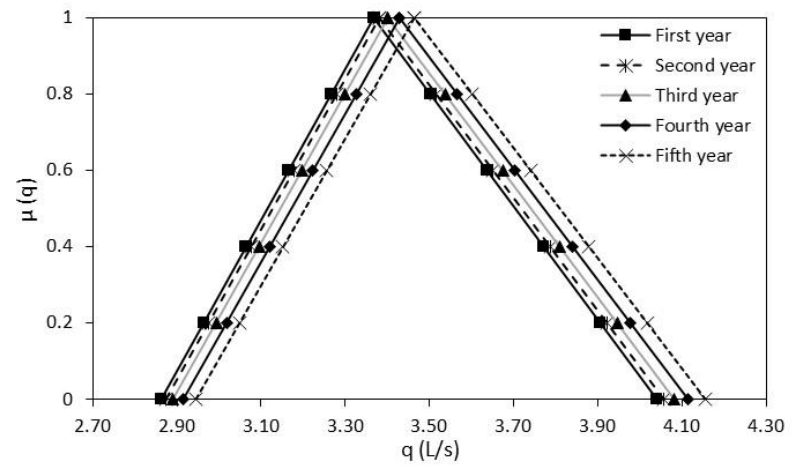

Fig. 4 Membership function of demand No. 54

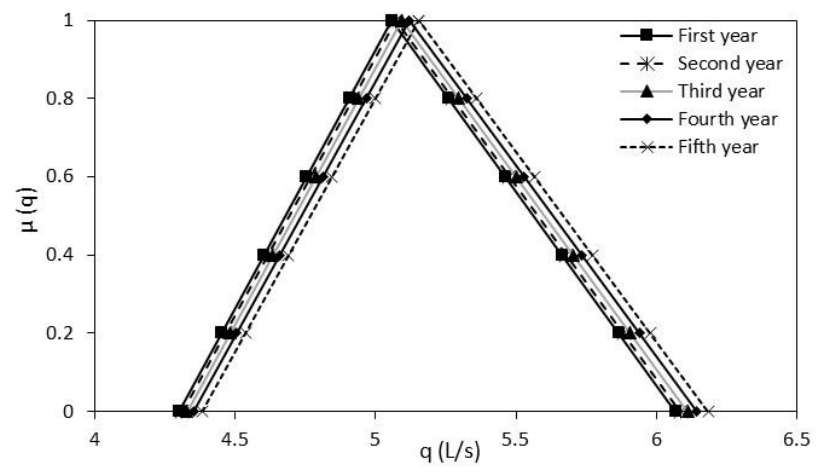

Fig. 6 Membership function of demand No. 104

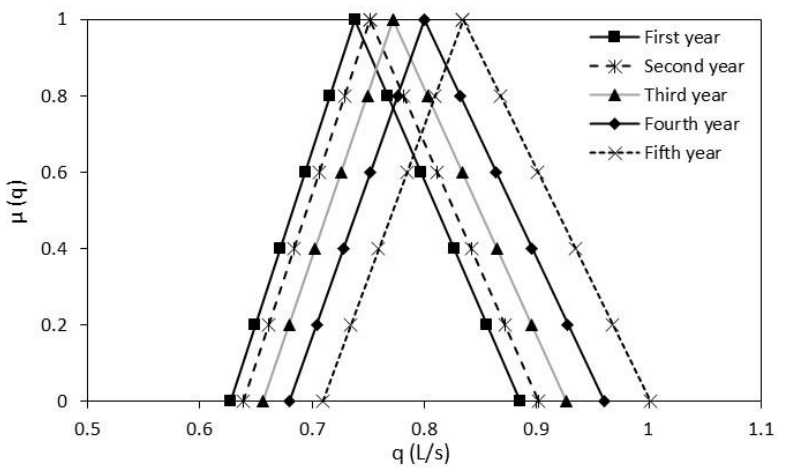

Fig. 5 Membership function of demand No. 41

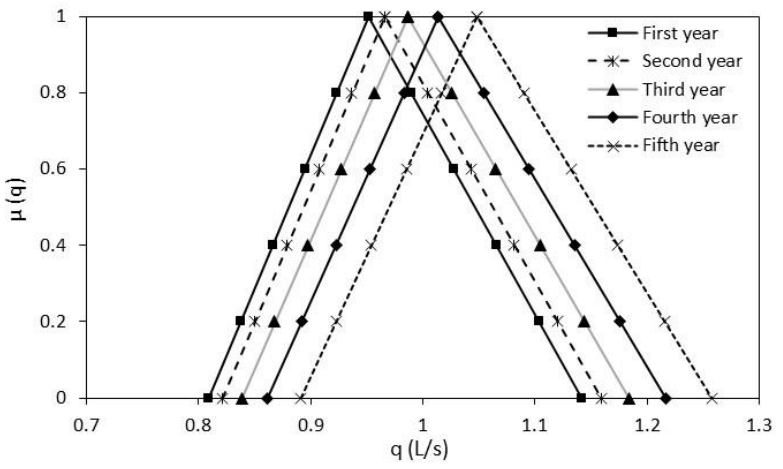

Fig. 7 Membership function of demand No. 63

As shown in Fig. 4, the crisp demand value of node 54 in the first year is $3.367(1 / \mathrm{s})$ and the base range of the node's membership function is between 2.86 and $4.04(1 / \mathrm{s})$. The crisp demand values of the node from the second to fifth years increase to $3.381,3.401,3.429$ and 3.463 (1/s), respectively, due to the covered population increase of this node.

The crisp demand value of node 63 in the first year, according to the covered population, is equal to $0.951(\mathrm{l} / \mathrm{s})$ and increases to the $0.965,0.986,1.013$ and $1.048(1 / \mathrm{s})$ during the project planning period. Despite the lower annual demand of node 63 compared to nodes 41, 54 and 104, the annual demand increasing rate of node 63 is higher than nodes 54, 41 and 104 because the node's annual demand increases exponentially.

Pipe's roughness coefficient changes during the planning period are calculated using Eq. (4) (Jafari 2020). Based on the equation, the pipe's roughness coefficient decreases with increasing the pipe's age. Therefore, pipe repair reduces the pipe roughness coefficient every year, while the pipes replacement increases the pipe roughness coefficient. Fig. 8 to Fig. 11 show the triangular fuzzy membership function of some pipe's roughness coefficient as example. According to the optimal pipes' replacement and repair instructions, only repair operations are recommended on the pipe 
no.16 during the project planning period (Jafari 2020). Therefore, the roughness coefficient of this pipe decreases during the planning period (Fig. 9). According to the optimal instruction, repair operations are recommended for pipe no.60 from the first to third year. In the fourth and fifth year, replacement and repair operations are recommended for this pipe, respectively (Jafari 2020). The roughness coefficient decreases from the first to third years, increases in the fourth year and finally decreases again in the fifth year.

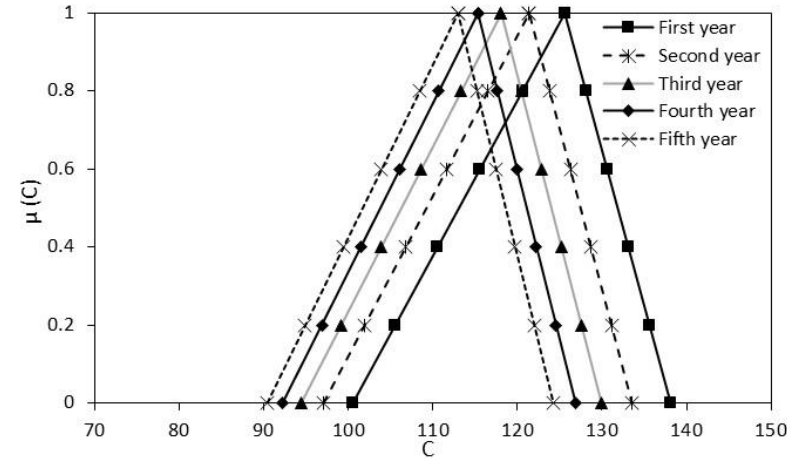

Fig. 8 Pipe roughness coefficient membership function of pipe No. 16

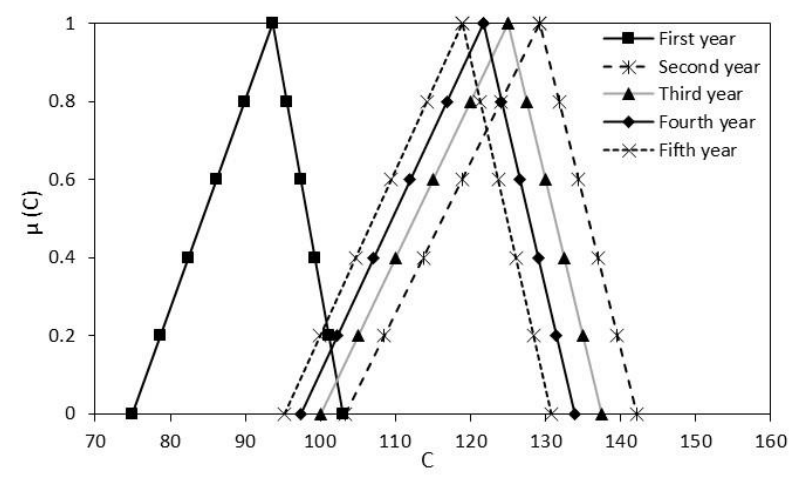

Fig. 10 Pipe roughness coefficient membership function of pipe No. 74

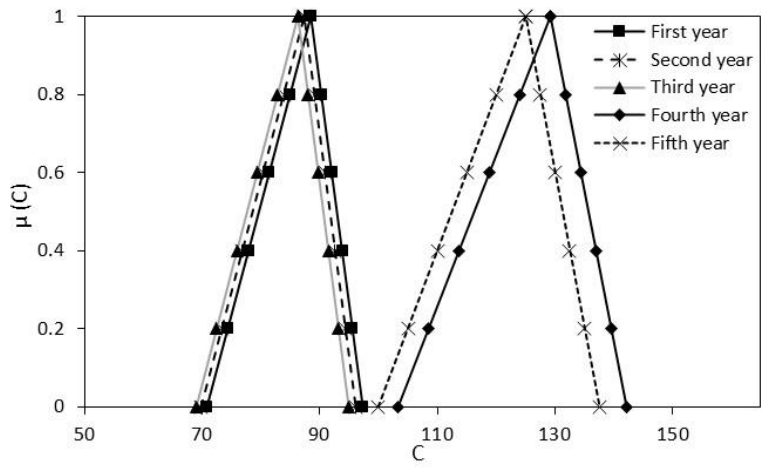

Fig. 9 Pipe roughness coefficient membership function of pipe No. 60

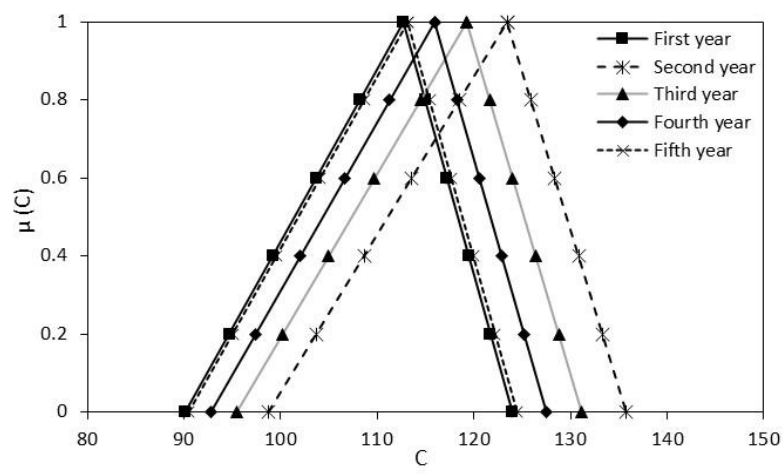

Fig. 11 Pipe roughness coefficient membership function of pipe No. 97

\subsection{Extract the interval of uncertain input parameters in each Fuzzy $\alpha$-cut}

After determining the fuzzy membership functions of the WDN uncertain input variables, including the pipes roughness coefficient and the nodes demand, fuzzy $\alpha$-cut method used to quantify these variables and obtain the input fuzzy set. In this study, five fuzzy $\alpha$-cuts perform on the fuzzy membership functions of these input variables. Since the nodes pressure as an uncertain output variable is uniform, only the extreme values (maximum and minimum) of each input 
variables fuzzy $\alpha$-cut are required to determine the extreme values and the fuzzy membership function of the output variable. Extreme values of the different fuzzy $\alpha$-cuts related to the nodes demand and the pipes roughness coefficient provide in Tables 4 and 5 as the example.

Table 4. Extreme values of the demand node No.54 during planning period (1/s)

\begin{tabular}{|c|c|c|c|c|c|c|c|c|c|c|}
\hline \multirow{2}{*}{$\alpha-$ Cut } & \multicolumn{5}{|c|}{ Min. } & \multicolumn{5}{c|}{ Max. } \\
\cline { 2 - 12 } & $\mathrm{Y}=1$ & $\mathrm{Y}=2$ & $\mathrm{Y}=3$ & $\mathrm{Y}=4$ & $\mathrm{Y}=5$ & $\mathrm{Y}=1$ & $\mathrm{Y}=2$ & $\mathrm{Y}=3$ & $\mathrm{Y}=4$ & $\mathrm{Y}=5$ \\
\hline 0 & 2.86 & 2.87 & 2.89 & 2.91 & 2.94 & 4.04 & 4.06 & 4.08 & 4.12 & 4.16 \\
\hline 0.2 & 2.96 & 2.98 & 2.99 & 3.02 & 3.05 & 3.91 & 3.92 & 3.95 & 3.98 & 4.02 \\
\hline 0.4 & 3.06 & 3.08 & 3.10 & 3.12 & 3.15 & 3.77 & 3.79 & 3.81 & 3.84 & 3.88 \\
\hline 0.6 & 3.17 & 3.18 & 3.20 & 3.22 & 3.26 & 3.64 & 3.65 & 3.67 & 3.70 & 3.74 \\
\hline 0.8 & 3.27 & 3.28 & 3.30 & 3.33 & 3.36 & 3.50 & 3.52 & 3.54 & 3.57 & 3.60 \\
\hline
\end{tabular}

Table 5 Roughness coefficient extreme values of the pipe No.60 during planning period

\begin{tabular}{|c|c|c|c|c|c|c|c|c|c|c|}
\hline \multirow{2}{*}{$\alpha-$ Cut } & \multicolumn{5}{|c|}{ Min. } & \multicolumn{5}{c|}{ Max. } \\
\cline { 2 - 11 } & $\mathrm{Y}=1$ & $\mathrm{Y}=2$ & $\mathrm{Y}=3$ & $\mathrm{Y}=4$ & $\mathrm{Y}=5$ & $\mathrm{Y}=1$ & $\mathrm{Y}=2$ & $\mathrm{Y}=3$ & $\mathrm{Y}=4$ & $\mathrm{Y}=5$ \\
\hline 0 & 70.83 & 69.90 & 69.30 & 103.37 & 100.01 & 97.39 & 96.11 & 94.91 & 142.14 & 137.52 \\
\hline 0.2 & 74.37 & 73.39 & 72.48 & 108.54 & 105.01 & 95.62 & 94.36 & 93.19 & 139.55 & 135.02 \\
\hline 0.4 & 77.91 & 76.89 & 75.93 & 113.71 & 110.01 & 93.85 & 92.62 & 91.46 & 136.97 & 135.52 \\
\hline 0.6 & 81.46 & 80.38 & 79.38 & 118.88 & 115.02 & 92.08 & 90.87 & 89.74 & 134.39 & 130.02 \\
\hline 0.8 & 85.00 & 83.88 & 82.83 & 124.05 & 120.02 & 90.31 & 89.12 & 88.01 & 131.80 & 127.52 \\
\hline
\end{tabular}

By combining the extreme values of the input variables, four scenarios obtain for each fuzzy $\alpha$-cut (Table 3). These scenarios considered as the input of the studied WDN simulation model to determine the fuzzy membership function of the output variable. As an example, the demand values of node No.54 and the roughness coefficient of pipe No.60 for the scenario S1 simulation are presented in Table 6.

Table 6 Demand values of node No.54 and roughness coefficient values of pipe No.60 in scenario S1

\begin{tabular}{|c|c|c|c|c|c|c|c|c|c|c|c|}
\hline & \multicolumn{2}{|c|}{$\alpha=0$} & \multicolumn{2}{|c|}{$\alpha=0.2$} & \multicolumn{2}{|c|}{$\alpha=0.4$} & \multicolumn{2}{|c|}{$\alpha=0.6$} & \multicolumn{2}{|c|}{$\alpha=0.8$} \\
\hline & & $\mathrm{q}(\mathrm{l} / \mathrm{s})$ & $\mathrm{C}$ & $\mathrm{q}(1 / \mathrm{s})$ & $\mathrm{C}$ & $q(1 / s)$ & $\mathrm{C}$ & $\mathrm{q}(1 / \mathrm{s})$ & $\mathrm{C}$ & $q(1 / s)$ & $\mathrm{C}$ \\
\hline$\ddot{U} \quad \bar{Z}$ & $\mathrm{Y}=1$ & 2.86 & 70.83 & 2.96 & 74.37 & 3.06 & 77.91 & 3.17 & 81.46 & 3.27 & 85.00 \\
\hline
\end{tabular}




\begin{tabular}{|c|c|c|c|c|c|c|c|c|c|c|c|}
\hline & $\mathrm{Y}=2$ & 2.87 & 69.90 & 2.98 & 73.39 & 3.08 & 76.89 & 3.18 & 80.38 & 3.28 & 83.88 \\
\cline { 2 - 11 } & $\mathrm{Y}=3$ & 2.89 & 69.30 & 2.99 & 72.48 & 3.10 & 75.93 & 3.20 & 79.38 & 3.30 & 82.83 \\
\cline { 2 - 11 } & $\mathrm{Y}=4$ & 2.91 & 103.37 & 3.02 & 108.54 & 3.12 & 113.71 & 3.22 & 118.88 & 3.33 & 124.05 \\
\cline { 2 - 10 } & $\mathrm{Y}=5$ & 2.94 & 100.01 & 3.05 & 105.01 & 3.15 & 110.01 & 3.26 & 115.02 & 3.36 & 120.02 \\
\hline
\end{tabular}

\subsection{Fuzzy membership function of the uncertain output variable}

The extreme values of the different pressure nodes, as the output of the simulation model, calculated after running the WDN simulation model based on the values of the input variables in each scenario and fuzzy cut. For example, the membership function of pressure nodes No. 104 and 63 during the planning period shown in Fig. 12 and Fig. 13.


Fig. 12 Fuzzy membership function of pressure node No.104 for four scenarios during planning period
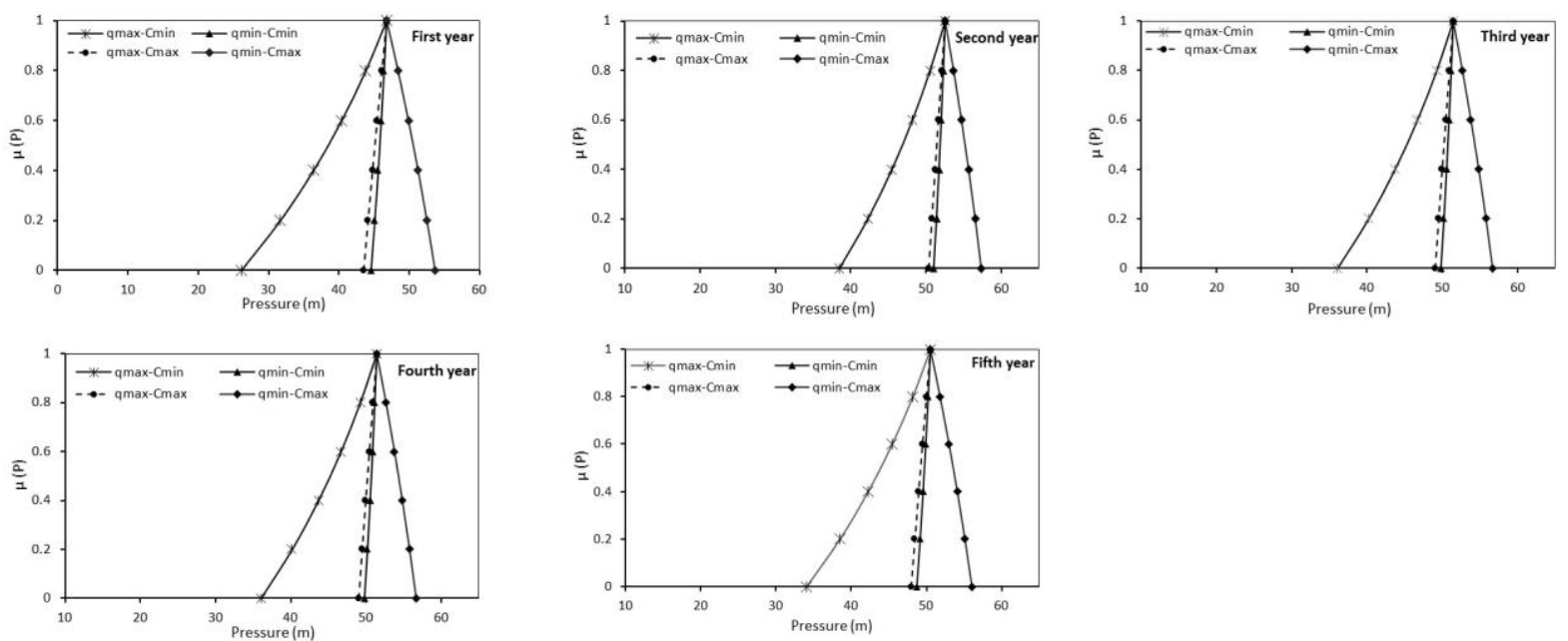

Fig. 13 Fuzzy membership function of pressure node No.63 for four scenarios during planning period 
As shown in Figures 12 and 13, the pressure node membership function is triangle in which this function stems are not linear that indicates the nodes pressure is uniform and nonlinear due to the changes of the nodes demand and pipes roughness coefficient. Nodes pressure in scenarios S3 and S2 and each fuzzy $\alpha$-cut have the maximum and minimum values between the four scenarios, respectively. The pressure values of scenarios S1 and S4 are in the range of the scenarios S2 and S3 pressure values. Therefore, S2 and S3 scenarios pressure values considered as the lower and upper limit of the nodes pressure triangular fuzzy membership function. In scenario S2, the nodes pressure conditions are critical, so in this study, it is called the "critical scenario".

According to Fig.12, in the scenario S2, for fuzzy $\alpha$-cut less than 0.4, node No.104 will always face a pressure shortage during the design planning period because the nodes available pressure is less than the nodes required pressure. In scenarios S1, S3 and S4 for all fuzzy $\alpha$-cuts, the required pressure and demand of node 104 will be met. In the critical scenario (S2) for fuzzy $\alpha$-cuts greater than 0.4 , the nodes required pressure is supplied.

In node No.63 and for critical scenario (S2), only for fuzzy $\alpha$-cut less than 0.2 , the required pressure demand is not supplied. In the rest of the scenarios, including S1, S3, and S4, the node required pressure is always supplied for all fuzzy $\alpha$-cuts.

\subsection{Uncertainty analysis of the WDN nodes pressure}

Scenario S2: Scenario S2 is the critical scenario of the studied WDN, therefore, first the nodes pressure in the scenario investigated. Figures14 to 19 show the nodes pressure of the studied WDN in this scenario during the planning period. 


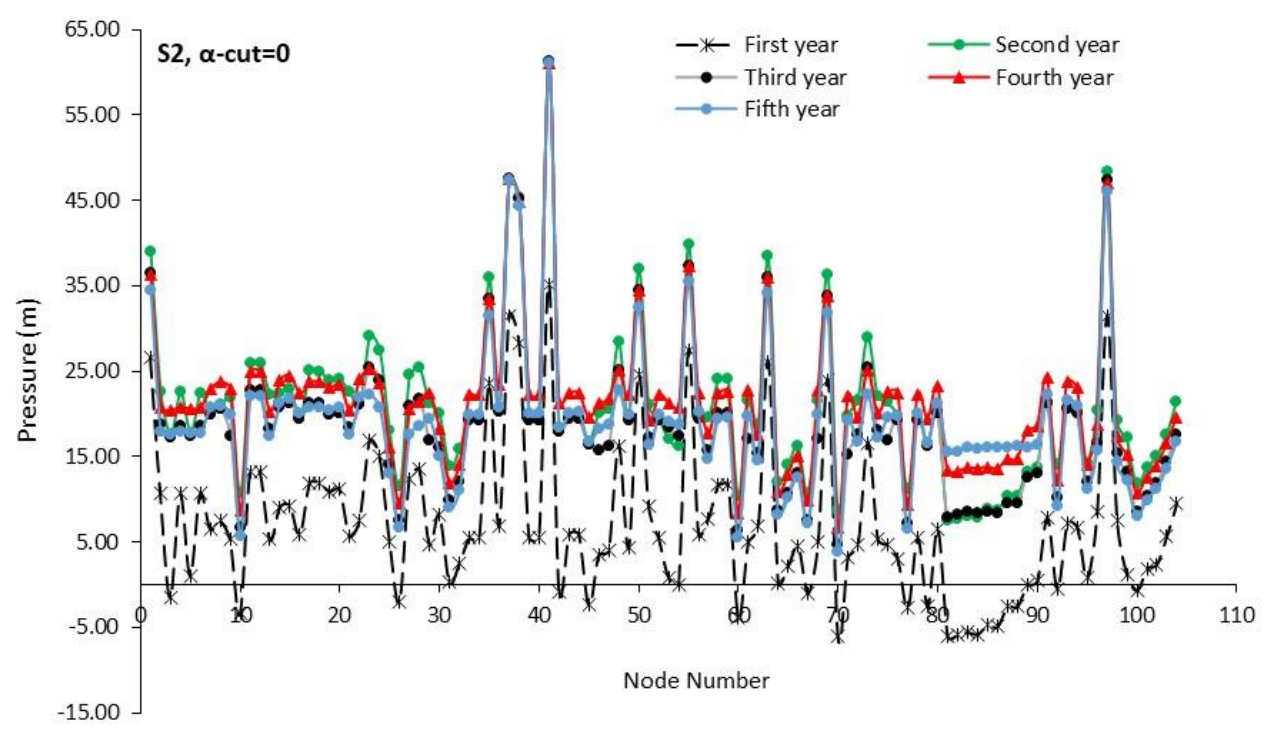

Fig. 14 Node's pressure of the studied WDN in the Scenario S2 and $\alpha=0$ during the project planning period

As Fig.14 shows, in the critical scenario (S2) and zero fuzzy $\alpha$-cut $(\alpha=0)$, i.e., the maximum uncertainty level of the input variables, in the first year after the implementation of the optimal pipes repair and replacement instructions, the required pressure of most nodes is not supplied. In this case, the required pressure of 3 nodes is supplied and the rest nodes have a lack of pressure. Out of 101 nodes that have pressure deficiency, 22 nodes have negative pressure. Due to the nodes demand increase and also the pipes roughness coefficient decrease in this scenario, the pipes hydraulic head loss increases significantly and as a result the hydraulic grade line located lower than the pipe and leads to negative pressure in some nodes. Negative pressure in the nodes not only does not supplied the nodes required demand but also causes cavitation in the pipes. Cavitation in the WDN pipes causes the pipes wall corrosion and weaking and pipe failure as a result. The nodes average pressure in these conditions is equal to 6.78 meters. From the second to the fifth year, the nodes pressure situation will be better than the first year, so that the nodes average pressure in the second to fifth years is $28.73,18.46,21.12$ and 18.92 meters, respectively. Jafari (2021) stated that the nodes pressure improvement in the second years after is due to the implementation of the optimal pipe repair and replacement instruction.

In the critical scenario S2 and reduce uncertainty level, i.e., $\alpha=0.2$, despite the nodes pressure improvement compared to $\alpha=0$, in the first year only 8 nodes and in the second to fifth years respectively $22,13,21$ and 12 nodes have a pressure higher than the required pressure and in the 
remaining nodes there will still be a lack of pressure (Fig. 15). In fuzzy $\boldsymbol{\alpha}-$ cut 0.2 , the nodes average pressure in the first to fifth year is equal to $15.38,27.035,257.87,27.36$ and 25.47 meters, respectively.

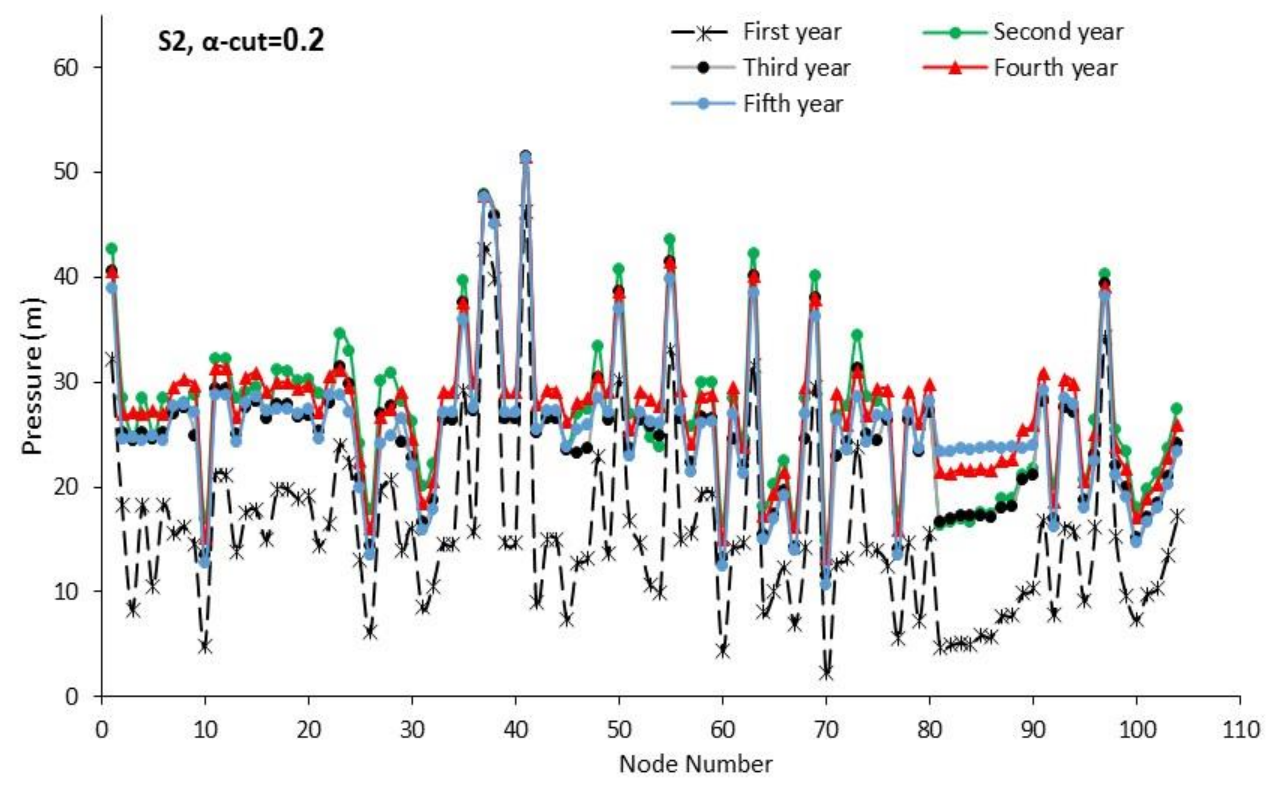

Fig. 15 Node's pressure of the studied WDN in the Scenario S2 and $\alpha=0.2$ during the planning period

In the critical scenario $(\mathrm{S} 2)$ and fuzzy $\alpha$ - cut 0.4 , the nodes pressure deficiency in the first year is significant, so that 93 nodes have pressure deficiency. From the second to fifth years, 32, 41, 31 and 32 nodes have pressure deficiency, respectively. The nodes average pressure from the first to fifth years are 22.35, 32.37, 30.69, 32.65 and 31.03 meters, respectively. Surveying the nodes pressure in fuzzy $\boldsymbol{\alpha}$ - cut levels higher than 0.4 , shows that the required pressure of most nodes is supplied due to reducing the input variables uncertainty range and approaching to the crisp values (Fig. 16). 


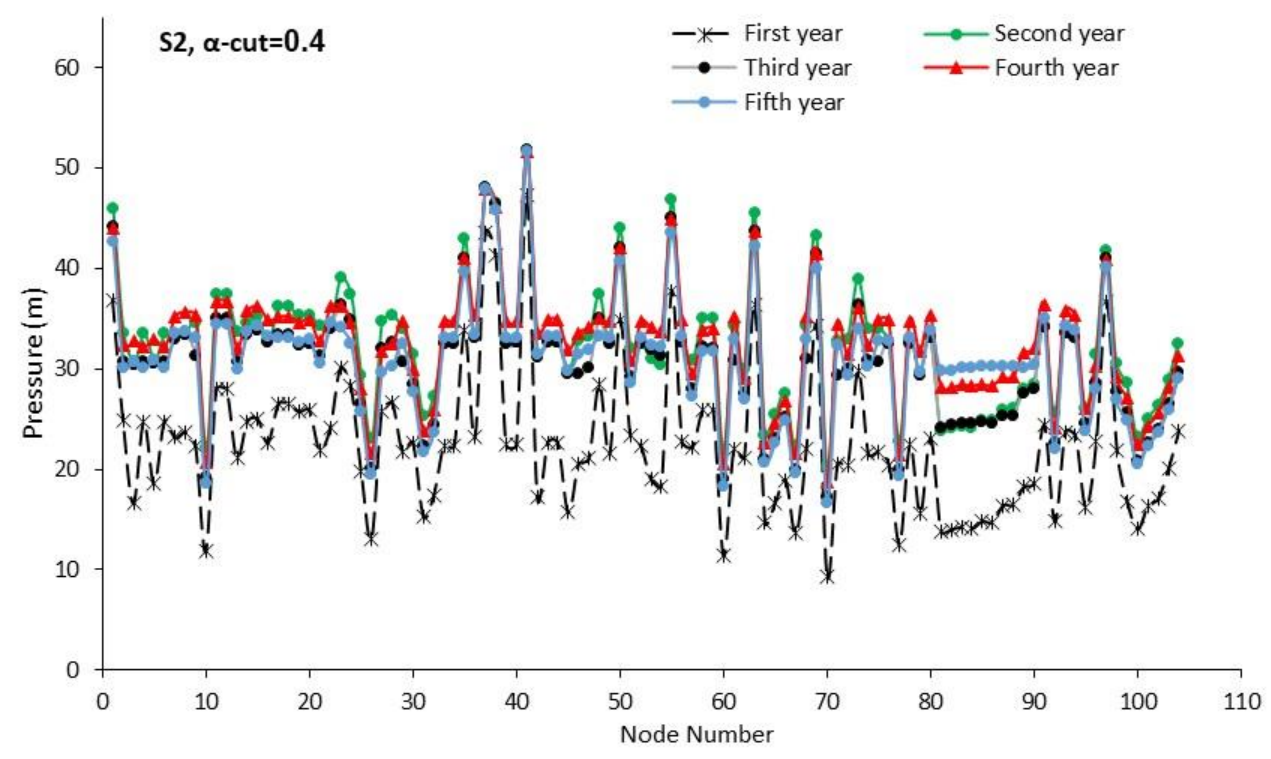

Fig. 16 Node's pressure of the studied WDN in the Scenario S2 and $\alpha=0.4$ during the planning period

Scenario S3: In scenario S3, the combination of the minimum demand values of each node and the maximum roughness coefficient of each pipe was considered as the simulation model input, and therefore the pipes longitudinal head loss and the nodes pressure values will be the minimum and maximum, respectively. As mentioned in the paragraphs above, the node pressure values in scenario S3 include the upper limit or the maximum values of the nodes pressure triangular fuzzy membership functions. In this scenario, the required pressure and consequently demand of all nodes supplied during the project planning period. Fig. 17 shows the WDN nodes pressure in scenario S3 and the zero fuzzy $\alpha$ - cut during the planning period. 


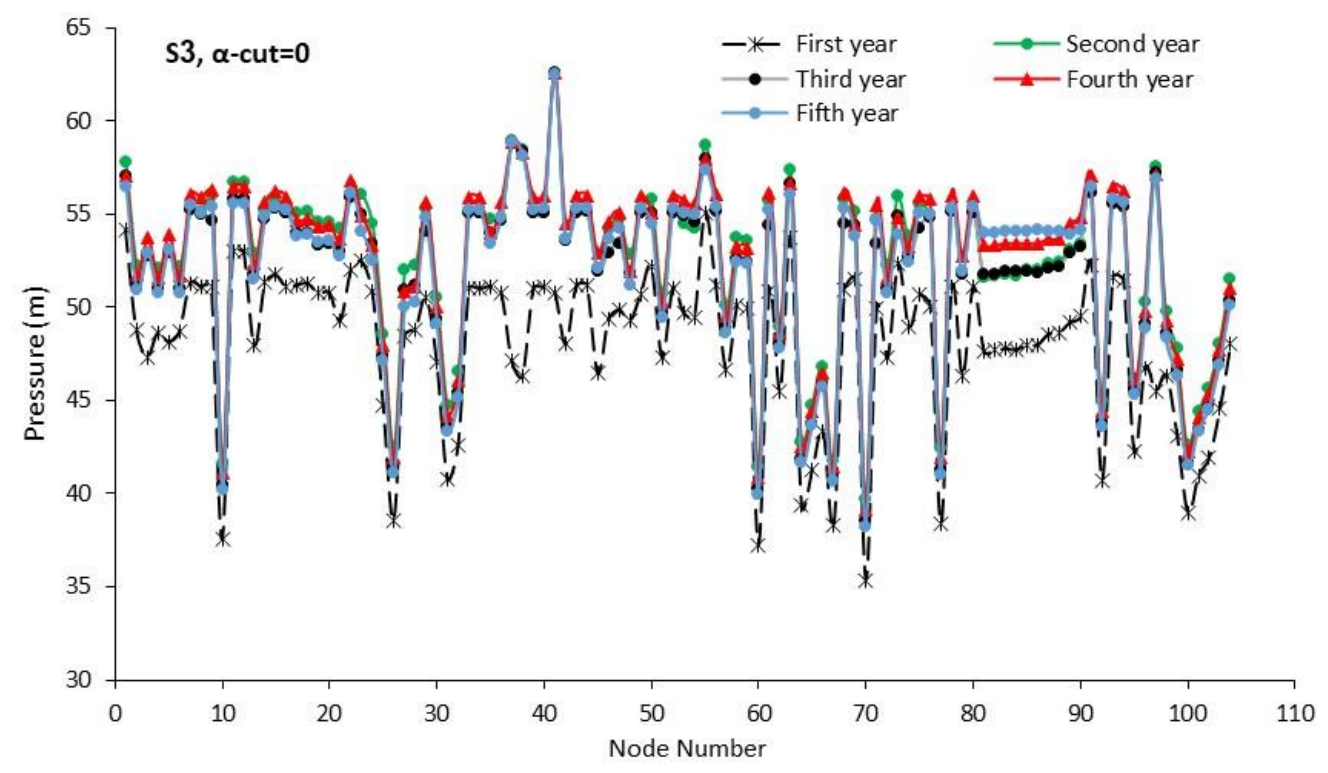

Fig. 17 Node's pressure of the studied WDN in the scenario S3 and $\alpha=0$ during the planning period

In this scenario, at the highest input parameters level uncertainty, the nodes average pressure of from the first to fifth years are 48.12, 52.48, 51.82, 52.59 and 51.95 meters, respectively. At higher fuzzy uncertainty levels i.e., fuzzy $\alpha-$ cut $0.2,0.4,0.6$ and 0.8 , the required pressure of all nodes is supplied.

Occurrence of pressure higher than the maximum allowable pressure in the WDN nodes causes various issues and problems such as pipes burst, leakage. Therefore, observing the maximum allowable values of the nodes pressure is also very important in the WDN design and operation. It is necessary to check the maximum allowable pressure in this S3 scenario because the values of this scenario are the upper limit of the triangular membership function.

Scenarios S1 and S4: scenario S1 is a combination of the minimum input variables including the nodes demand and the pipes roughness coefficient and scenario S4 is a combination of the maximum input variables. Figures 18 and 19 show the nodes pressure of the studied WDN in scenarios S1 and S4 and the highest input uncertainty level. As shows in Fig. 18, in scenario S4 and in the highest uncertainty level of the input variables, in the first year, 45 nodes out of 104 nodes (equivalent to $43 \%$ ) have a lower pressure than the required pressure. In the following years, the number of nodes with pressure deficiency decrease so that from the second to fifth years, 21, 23, 22 and 23 nodes have pressure deficiency, respectively. In this scenario, nodes pressure 
redundancy does not occur in the first year, but six nodes have pressure redundancy from the second to fifth years. Study of the higher uncertainty levels data of the input variables (i.e., fuzzy $\alpha$-cut greater than 0.2 ) shows that in this scenario the required pressure is supplied to most of the network nodes (more than $85 \%$ ).

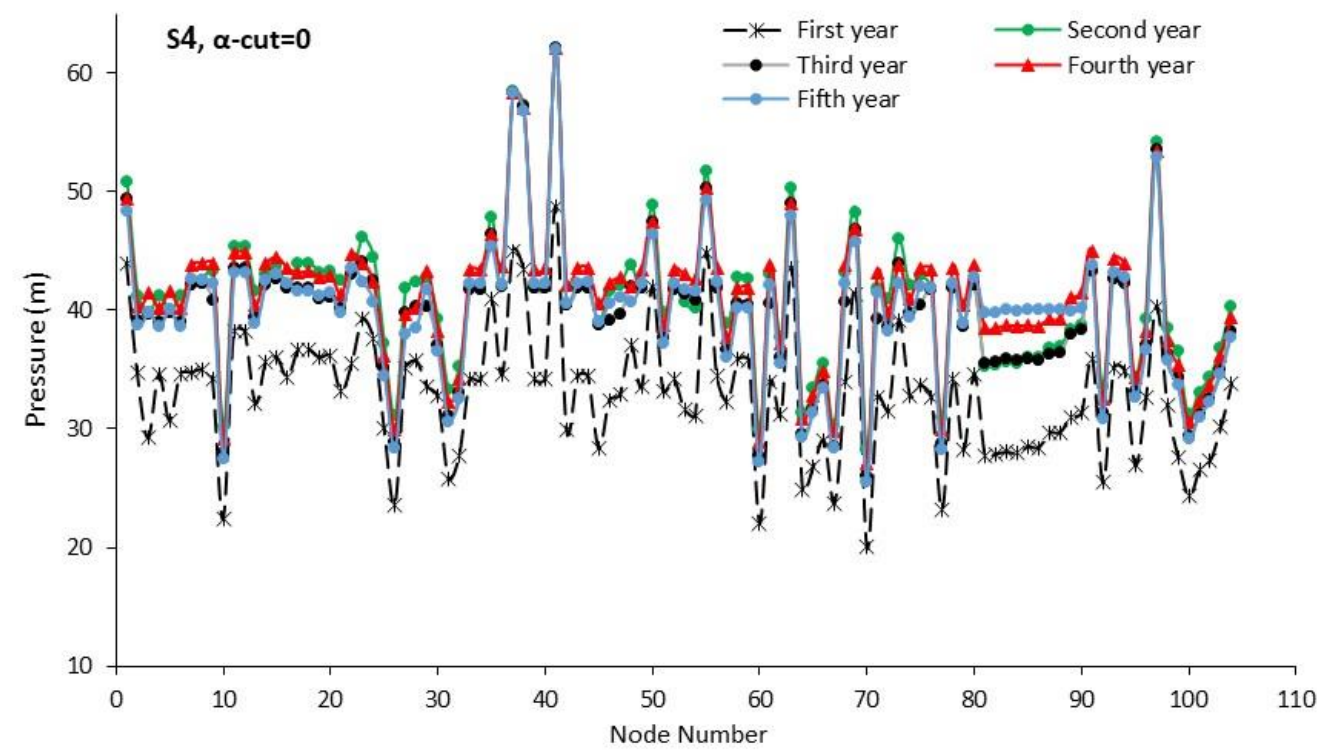

Fig. 18 Node's pressure of the studied WDN in the Scenario S4 and $\alpha=0$ during the planning period

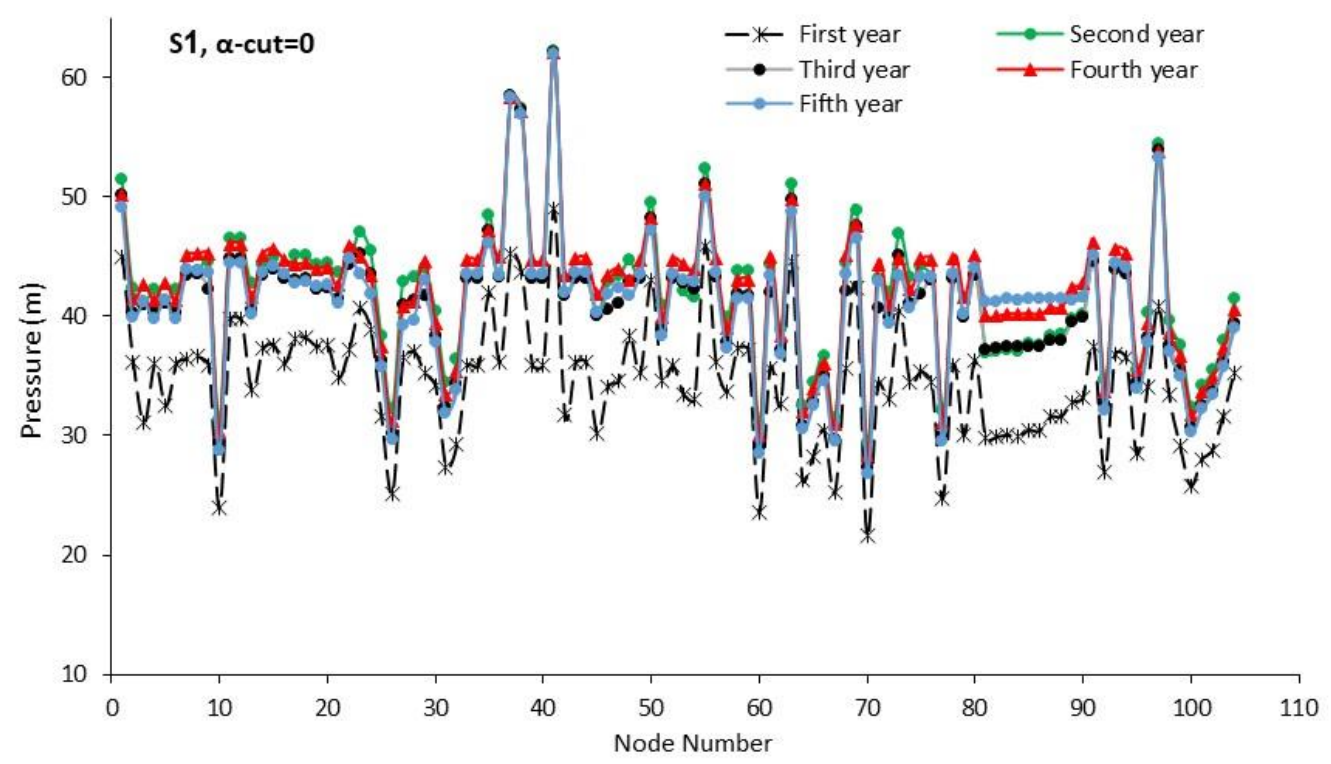

Fig. 19 Node's pressure of the studied WDN in the Scenario S1 and $\boldsymbol{\alpha}=\mathbf{0}$ during the project planning period 
In scenario S1 and the highest uncertainty level of the input variables, in the first year, 35 nodes out of 104 network nodes (equivalent to 33\%) have a pressure lower than the required pressure. In the following years, the number of nodes with pressure deficiency decrease so that from the second to fifth years, 12, 16, 13 and 16 nodes have pressure deficiency, respectively. In this scenario, the nodes pressure redundancy does not occur in the first year, but seven nodes have pressure redundancy per year from the second to fifth years.

Based on the above analysis, the nodes pressure deficiency of the studied WDN occurs in different scenarios and under the highest uncertainty level of the nodes demand and the pipes roughness coefficient. At the highest level of uncertainty, i.e., zero fuzzy $\alpha-$ cut, the uncertainty interval of the pipe roughness coefficient and the nodes demand are equal to $[-20+10]$ and $[-15+20]$ percent of the crisp values, respectively. The mean pressure uncertainty interval of the WDN nodes due to the uncertainty of the pipe roughness coefficient and nodes demand, at the highest uncertainty level presented in Table 7.

Table 7 Mean pressure uncertainty interval of the WDN nodes in the four scenarios and $\alpha=0$ during the planning period $(\%)$

\begin{tabular}{|c|c|c|c|c|c|}
\hline Year & First & Second & Third & Fourth & Fifth \\
\hline S1 & -9 & -8.4 & -6.2 & -5.6 & -6 \\
\hline S2 & -84 & -54 & -58 & -53 & -58 \\
\hline S3 & 27 & 18 & 19 & 18 & 19 \\
\hline S4 & -13 & -8.4 & -9.1 & -8.3 & -8.9 \\
\hline
\end{tabular}

The negative and positive signs in Table 7, indicate the decrease and increase of the nodes pressure due to input variables uncertainty compared to the crisp value. According to this table, in the critical scenario (S2) and the highest uncertainty level, the average pressure uncertainty interval of the WDN nodes is negative and between 53 to $84 \%$ (in different years). In other words, in this scenario and the highest uncertainty level of the studied WDN input variables, the nodes pressure significantly reduce (more than 50\%). In the condition, the WDN nodes pressure is much less than the minimum allowable pressure, so the uncertainty interval of the nodes pressure (in this scenario and zero fuzzy $\alpha-$ cut) is unacceptable and will cause many operational problems. In Scenario 
$\mathrm{S} 3$, the average pressure uncertainty interval of the WDN nodes is positive and between $18 \%$ and $27 \%$ (in different years). Despite the pressure increase, the pressure of different network nodes is still lower than the allowable pressure, so in the scenario and zero fuzzy $\alpha-$ cut, the pressure uncertainty intervals are acceptable. In scenarios S1 and S4, the average interval of node pressure uncertainty is always negative and changes from 5.6 to $13 \%$ (in different years). With the pressure reduction, the nodes pressure is always higher than the minimum allowable pressure and is acceptable.

\subsection{WDN reliability under uncertainty condition}

In order to evaluate the WDN hydraulic performance under the nodes demand and pipes roughness coefficient uncertainty, the network reliability index $\left(\mathrm{Re}_{\mathrm{sys}}\right)$ developed by Jafari 2020 is used. The hydraulic reliability index values of the studied WDN under scenario S2 during the planning period, are presented in Fig. 20.

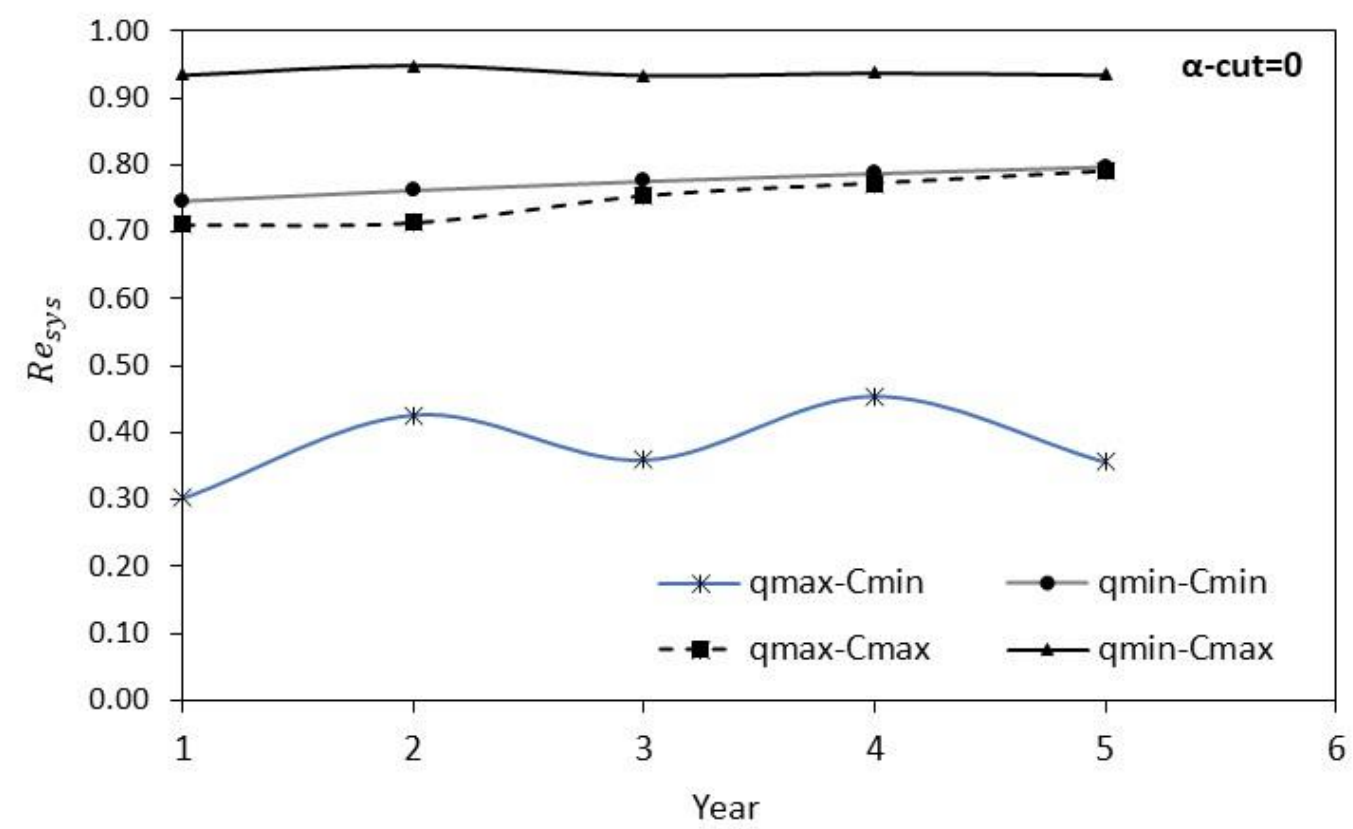

Fig. 20 Reliability index values of the studied WDN in the four Scenario and $\alpha=0$ during the planning period

As shown in Fig. 20, in the critical scenario (S2) and the highest uncertainty level of the input variables (i.e., zero fuzzy $\alpha-$ cut), the studied WDN reliability index is very low and in the range of 0.3 to 0.42 during the planning period because of the pressure deficiency in most of the WDN 
nodes. Reliability index values fluctuation in the S2 scenario during the planning period is due to the nodes pressure fluctuations (decreases or increases) in different years. In scenario S3, the reliability index values in highest uncertainty level of the input variables are in the range of 0.93 during the planning period. The high reliability index in this scenario is due to supplying the required pressure of the WDN nodes. Therefore, the WDN has acceptable performance. In scenarios S1 and S4, the reliability index values are in the range of 0.70 to 0.80 during the planning period, due to the pressure supply of a large number of the WDN nodes. Despite the high uncertainty level of the input variables, the studied WDN performance in these two scenarios is relatively good.

In the critical scenario (S2) and the lower uncertainty level (i.e., $\alpha=0.2$ ), the WDN reliability index in the first year, is less than 0.50, which indicates low WDN performance. Failure to supply pressure of most network nodes causes reducing the WDN hydraulic performance (Fig. 21).

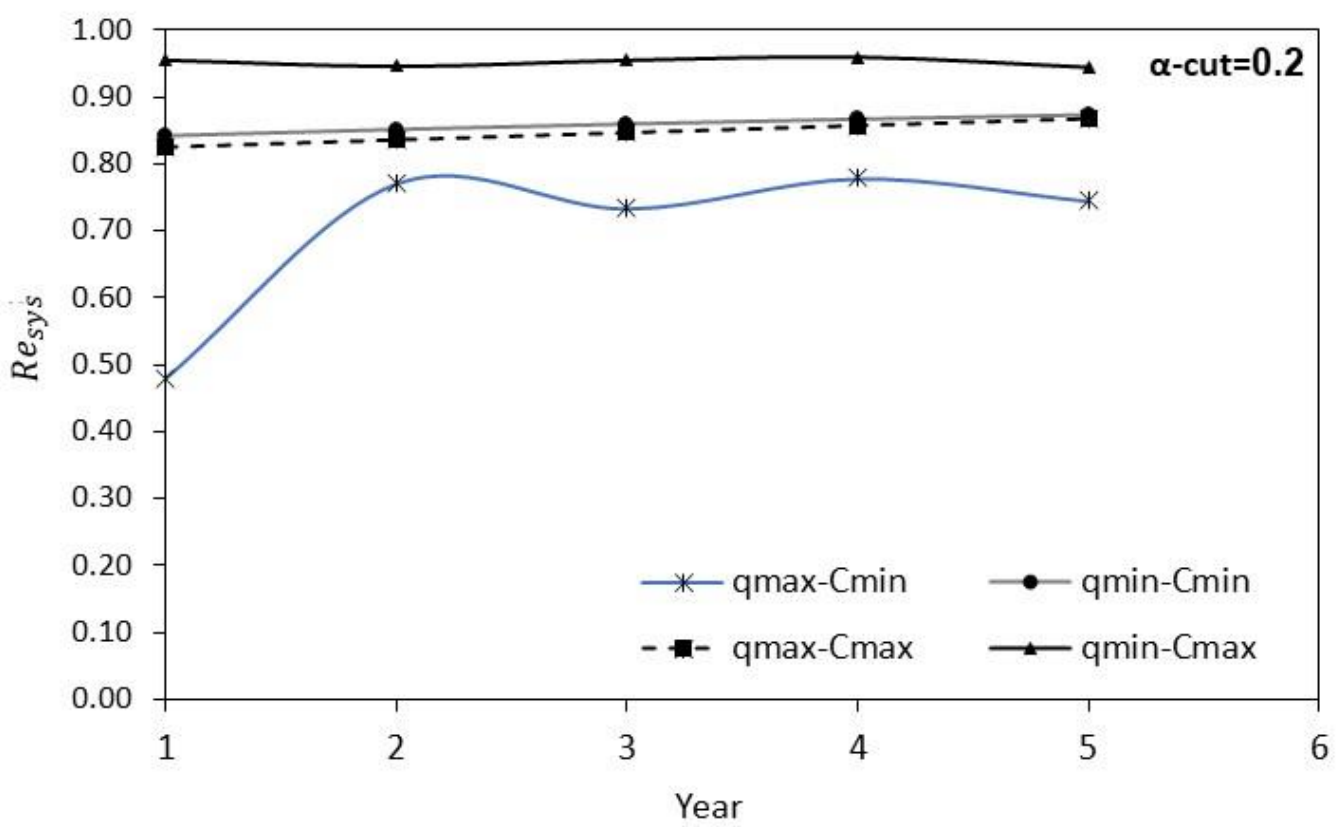

Fig. 21 Reliability index values of the studied WDN in the four Scenario and $\boldsymbol{\alpha}=\mathbf{0 . 2}$ during the planning period

Study of the WDN reliability index values at the lower uncertainty level of the input variables (i.e., $\alpha=0.4,0.6$ ), shows that the index values are still about 0.70 to 0.80 in the first year of the design planning period. However, the index values, even in the critical scenario, are more than 0.85 , from 
the second to fifth years, which indicates acceptable performance of the WDN (Figures 22 and 23).

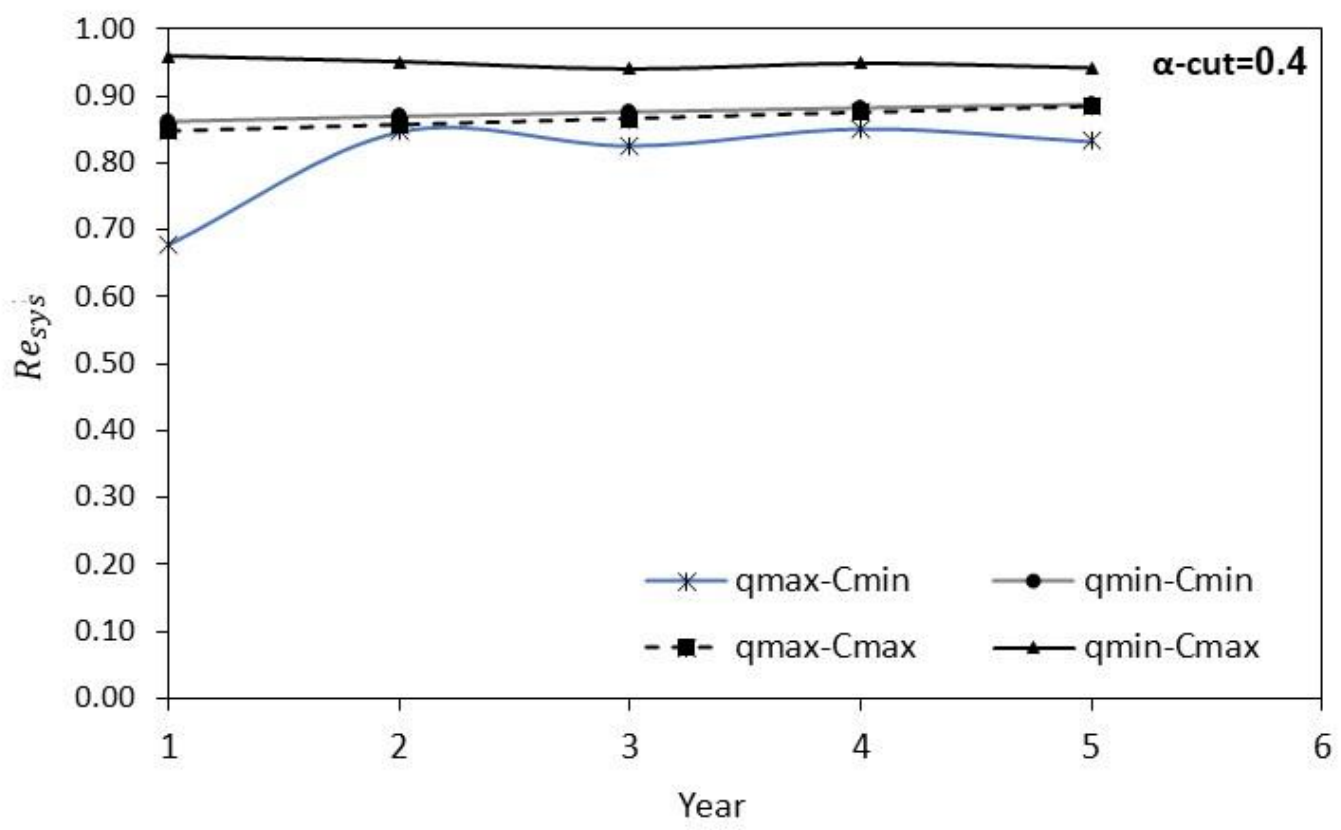

Fig. 22 Reliability index values of the studied WDN in the four Scenario and $\boldsymbol{\alpha}=\mathbf{0 . 4}$ during the project planning period

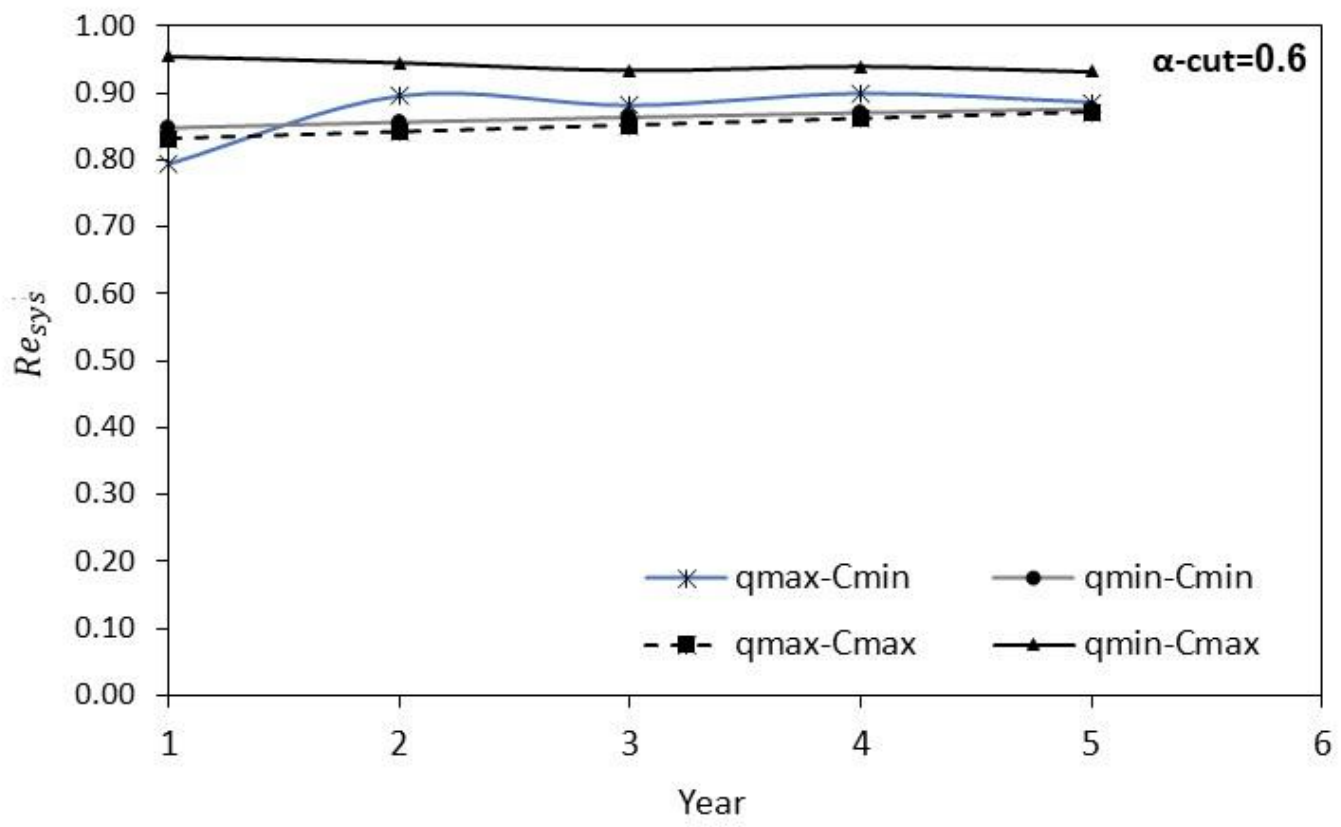

Fig. 23 Reliability index values of the studied WDN in the four Scenario and $\boldsymbol{\alpha}=\mathbf{0 . 6}$ during the project planning period 
Based on the uncertainty interval of the WDN input variables, the average uncertainty interval of the reliability index, in four scenarios and the highest uncertainty level (i.e., $\alpha=0$ ) is presented in Table 8.

Table 8 Average uncertainty interval of the WDN reliability index, in four scenarios and the highest uncertainty level (i.e., $\alpha=0)(\%)$

\begin{tabular}{|c|c|c|c|c|c|}
\hline Year & First & Second & Third & Fourth & Fifth \\
\hline S1 & -12 & -17 & -14 & -18 & -16 \\
\hline S2 & -64 & -53 & -60 & -52 & -62 \\
\hline S3 & 10 & 3 & 2.6 & $2-$ & $1.6-$ \\
\hline S4 & -16 & -22 & -17 & -19 & -17 \\
\hline
\end{tabular}

The negative and positive signs in Table 8 , indicate the decrease and increase of the reliability index due to the input variable uncertainty compared to the crisp input variables. According to this table, in the critical scenario (S2) and the highest uncertainty level of input variables, i.e., a $20 \%$ decrease in pipes roughness coefficient and a $20 \%$ increase in nodes demand, the reliability index uncertainty of the WDN is between $-52 \%$ and $-64 \%$. during the project planning period. The crisp value of the WDN reliability index in this scenario is very low and about 0.30 to 0.40 , so with a decrease of 52 to $64 \%$ due to the input's uncertainty, the index values reduce to less than 0.2 , which indicates WDN performance is very low at the highest uncertainty level of the input variables. In scenario S3 and the highest uncertainty level of input variables, the mean uncertainty interval of the WDN reliability index is between -2 to 10 percent which considering the index crisp values in scenario $\mathrm{S} 3$, the reliability index values is always more than 0.9 .

In Scenario S1 and zero fuzzy $\alpha$ - cut, the reliability index values are in the range $12 \%$ to $18 \%$ during the project planning period. In uncertain condition, the reliability index values are always more than 0.70 due to the crisp value of this index.

In S4 scenario and zero fuzzy $\alpha$ - cut, the uncertainty of the reliability index values also decreases and is in the acceptable range of $16 \%$ to $22 \%$. The index value in uncertain conditions is always more than 0.68. At higher uncertainty levels, except in the first year, the reliability index uncertainties are always less than $15 \%$. 


\section{Conclusion}

In this research, the uncertainty analysis of Gorgan city WDN performed after implementing the optimal pipes repair and replacement instruction provided by Jafari (2020). Pipe roughness coefficient and node demand considered as WDN uncertain input variables and the node pressure during the planning period (5 years) considered as WDN uncertain output variable. The fuzzy $\alpha$ cut method used to quantify the uncertainty of the WDN input variables and investigate their effect on the WDN output variables. A triangular membership functions selected for the uncertain input and output variables, based on the variable's nature and recorded data. The values of the membership functions, after normalization, were in the range of zero and one. In the fuzzy $\alpha$-cut method, the fuzzy set contains all the input extreme values smaller than or equal to the $\alpha$-cut. The extreme values (maximum and minimum) of the input variables in each fuzzy $\alpha$-cut derived from the variable's fuzzy membership functions. In order to investigate the simultaneous effect of input uncertainty variables, the extreme values combinations of two uncertain input variables considered as four different scenarios. The first scenario (S1) is the combination of the minimum nodes demand values and the roughness the pipes roughness coefficient. The fourth scenario (S4) is the combination of the maximum nodes demand values and the pipes roughness coefficient. In the second scenario (S2), the minimum pipe roughness coefficient values and the maximum nodes demand values are combined, and in the third scenario (S3), the maximum pipes roughness coefficient values and the minimum nodes demand values are combined. Study of the nodes pressure changes due to changes two input variables including the nodes demand and pipe roughness coefficient show that the nodes pressure (as an output variable) is a uniform variable. Therefore, the WDN hydraulic simulation performed using the extreme values of four scenarios in different fuzzy $\alpha$-cut to obtain the nodes pressure fuzzy membership functions. Node pressure membership functions show that the node pressure values, in scenario S2, have always the minimum values of the node pressure fuzzy membership function and so this scenario called the critical scenario. In the critical scenario (S2) and the highest uncertainty level of uncertainty (i.e., zero fuzzy $\alpha$-cut), in the first year of the project planning period, about $22 \%$ of the WDN nodes have negative pressure and the required pressure of only $3 \%$ of the WDN nodes supplied. In the following years, the pressure deficiency is still observed in most WDN nodes, so that the required pressure is supplied to only about $8 \%$ of the nodes. Therefore, the WDN reliability index is very low and between 0.3 to 0.4 . By reducing the uncertainty level to $\alpha$-cut equal 0.2 , most of the nodes 
still have the pressure deficiency and the WDN reliability index is less than 0.7 . The pressure values of the WDN nodes, in scenario S3, constitute the pressure nodes upper limit of the fuzzy membership functions. In the scenario, the required pressure of all nodes is always supplied even in the highest uncertainty level of the input variables, during the project planning period. Therefore, the WDN reliability index values are always more than 0.93. In scenario S1 and fuzzy $\alpha$-cut less than 0.2 (i.e., very high uncertainty levels of the input variables), the required pressure of major parts of the network nodes, except in the first year. Therefore, the WDN reliability index is always more than 0.8 . In scenario $\mathrm{S} 4$, similar to scenario $\mathrm{S} 1$, in fuzzy $\alpha$-cut less than 0.2 , the required pressure of about $45 \%$ of the WDN nodes is not supplied, in the first year. So, the WDN reliability index is about 0.7 . In the following years, the WDN reliability index increases up to 0.85 because of the nodes pressure improvement. Study of the uncertainty interval of the nodes pressure and the reliability index show that only in the critical scenario (S2) and the highest uncertainty level of the input variables (i.e., zero fuzzy $\alpha$-cut), uncertainty interval of the nodes pressure and the reliability index is very high and always more than 0.5 .

In general, the fuzzy uncertainty analysis of the studied WDN, after the optimal pipes repair and replacement instruction implementation (Jafari 2020), shows that:

- The studied WDN does not have acceptable performance only in scenario S2 and the highest uncertainty level of the input variables, so proper operation management is necessary . In other scenarios and uncertainty levels of the input variables, the hydraulic performance of the WDN is acceptable.

- The WDN performance, under the input variables uncertainty, can be analyzed with acceptable accuracy and low computational volume, by the fuzzy $\alpha$-cut method. Then the necessary decisions can be made to face the consequences of the uncertain input values.

- Using further fuzzy $\alpha$-cuts, in future studies, can improve the uncertainty analysis accuracy of WDNs.

- Using the fuzzy method to consider the input variables uncertainty in the optimization process of the pipes repair and replacement instructions in future studies can provide flexible instructions so that the WDN has an acceptable performance under uncertainty input variables.

\section{Compliance with ethical standards}

Conflict of interest The authors declare that they have no conflict of interest. 
Funding details Not Applicable

Ethical approval This article does not contain any studies with human participants or animals performed by any of the authors.

Informed Consent Not Applicable

Authorship contributions S. M. Jafari: Conceptualization, Methodology, Data acquisition,

Writing- Original draft preparation; A. R. Zahiri: Supervision, editing of manuscript; O. Bozorg Hadad: Supervision, editing of manuscript; Mahmoud Mohammad Rezapour Tabari: Conceptualization, Supervision, Methodology, Visualization, Editing of manuscript

\section{References}

Abebe AJ, Guinot V, Solomatine DP (2000) Fuzzy alpha-cut vs. Monte Carlo techniques in assessing uncertainty in model parameters. In Proceedings of 4th international conference on hydroinformatics, Cedar Rapids.

Amirabdollahian M, Chamani MR, Asghari K (2011) Optimal design of water networks using fuzzy genetic algorithm. In Proceedings of the Institution of Civil Engineers-Water Management 164(7): 335-346

Baños R, Reca J, Martínez J, Gil C, Márquez AL (2011) Resilience indexes for water distribution network design: a performance analysis under demand uncertainty. Water resources management 25(10):2351-2366

Bao Y, Mays LW (1990) Model for water distribution system reliability. Journal of Hydraulic Engineering 116(9): 1119-1137

Bozorg-Haddad O, Ghajarnia N, Solgi M, Loáiciga HA, Mariño MA (2017) Multi-objective design of water distribution systems based on the fuzzy reliability index. Journal of Water Supply: Research and Technology-AQUA 66(1): 36-48

Branisavljevic N, Ivetic M (2006) Fuzzy approach in the uncertainty analysis of the water distribution network of Becej. Civ. Eng. Environ. Syst. 23(3): 221-236

Braun M, Piller O, Deuerlein J, Mortazavi I, Iollo A (2020) Uncertainty quantification of water age in water supply systems by use of spectral propagation. Journal of Hydroinformatics 22(1): $111-120$ 
Dandy GC, Engelhardt MO (2006) Multi-objective trade-offs between cost and reliability in the replacement of water mains. Journal of water resources planning and management 132(2): 7988

Dini M, Tabesh M (2018) A New Reliability Index for Evaluating the Performance of Water Distribution Network. Journal of Water and Wastewater 29(3): 1-16 (In Persian).

Dongre SR, Gupta R (2017) Optimal design of water distribution network under hydraulic uncertainties. ASCE-ASME J. Risk Uncertainty Eng. Syst. 3(3): 1-11

Dridi L, Mailhot A, Parizeau M, Villeneuve JP (2009) Multi-objective approach for pipe replacement based on Bayesian inference of break model parameters. Journal of Water Resources Planning and Management 135(5): 344-354

Dridi L, Parizeau M, Mailhot A, Villeneuve JP (2008) Using evolutionary optimization techniques for scheduling water pipe renewal considering a short planning horizon. Computer-Aided Civil and Infrastructure Engineering 23(8): 625-635

Farmani R, Savic DA, Walters GA (2005a) Evolutionary multi-objective optimization in water distribution network design. Engi. Opti. 37(2): 167-183

Farmani R, Savic DA, Walters GA (2005b) Fuzzy rules for hydraulic reliability-based design and operation of water distribution systems. In: Proc., Impacts of Global Clim. Change, 1-9

Fu G, Butler D, Khu ST, Sun SA (2011) Imprecise probabilistic evaluation of sewer flooding in urban drainage systems using random set theory. Water Resources Research 47(2), https://doi.org/10.1029/2009WR008944

Geranmehr M, Asghari K, Chamani MR (2019) Uncertainty analysis of water distribution networks using type-2 fuzzy sets and parallel genetic algorithm. Urban Water Journal 16(3): 193-204

Gheisia A, Nasera G (2015) Multi-aspect performance analysis of water distribution systems under pipe failure. Procedia Engineering 119: 158-167

Gupta R, Bhave PR (2007) Fuzzy parameters in pipe network analysis. Civ. Eng. Environ. Syst. 24(1): $33-54$

Gupta R, Harkutiya J, Dongre S, Ormsbee L (2014) Fuzzy analysis of pressure-deficient water distribution networks. In: Proc., World Env. and Water Resourc. Cong. 435-444

Haghighi A, Asl AZ (2014) Uncertainty analysis of water supply networks using the fuzzy set theory and NSGA-II. Eng. Appl. Artif. Intell. 32: 270-282 
Ivetić M (1996) Control Valves-Principles of Operation. In Water Supply Systems, Springer, Berlin, Heidelberg, 145-159

Jafari SM, Zahiri AR, Bozorg-Haddad O, Tabari MMR (2020) New Approach for Prediction of Water Distribution Network Pipes Failure Based on an Intelligent Hybrid Model (Case Study: Gorgan Water Distribution Network), Journal of water and soil conservation 27(5): 149-166 (in persion).

Jafari SM (2020) Multi-objective optimization of water distribution systems under demand and roughness uncertainties and pipe breakages, Ph.D. Thesis, Gorgan university of Agriculture science and natural resources.

Jafari SM, Zahiri AR, Hadad OB, Tabari MMR (2021) A hybrid of six soft models based on ANFIS for pipe failure rate forecasting and uncertainty analysis: a case study of Gorgan city water distribution network. Soft Computing 25(11): 7459-7478

Kapelan Z, Savic DA, Walters GA (2005) Decision-support tools for sustainable urban development. In Proceedings of the Institution of Civil Engineers-Engineering Sustainability 158(3): 135-142

Liu H, Savić DA, Kapelan Z, Creaco E, Yuan Y (2017) Reliability surrogate measures for water distribution system design: Comparative analysis. Journal of Water Resources Planning and Management 143(2): 04016072

Maier HR, Simpson AR, Zecchin AC, Foong WK, Phang KY, Seah HY, Tan CL (2003) Ant colony optimization for design of water distribution systems. Journal of water resources planning and management 129(3): 200-209

Maskey S, Guinot V, Price RK (2004) Treatment of precipitation uncertainty in rainfall-runoff modelling: a fuzzy set approach. Advances in water resources 27(9): 889-898

Moosavian N, Lence BJ, (2018) Approximation of fuzzy membership functions in water distribution network analysis. J. Hydraul. Eng. 144 (7): 04018039

Nemanja T (2006) Introduction to Urban Water Distribution. Netherland: Taylor and Francis.

Prasad TD, Park NS (2004) Multi-objective genetic algorithms for design of water distribution networks. Journal of Water Resources Planning and Management 130(1): 73-82

Revelli R, Ridolfi L (2002) Fuzzy approach for analysis of pipe networks. J. Hydraul. Eng. 128(1): 93-101 
Sabzkouhi AM, Haghighi A (2016) Uncertainty analysis of pipe-network hydraulics using a manyobjective particle swarm optimization. J. Hydraul. Eng. 142(9): 1-12

Scholten L, Scheidegger A, Reichert P, Mauer M, Lienert J (2014) Strategic rehabilitation planning of piped water networks using multi-criteria decision analysis. Water Research 49: 124-143

Seifollahi-Aghmiuni S, Haddad OB, Mariño MA (2013a) Water distribution network risk analysis under simultaneous consumption and roughness uncertainties. Water resources management 27(7): 2595-2610

Seifollahi-Aghmiuni S, Haddad OB, Omid MH, Mariño MA, (2013b) Effects of pipe roughness uncertainty on water distribution network performance during its operational period. Water resources management 27(5): 1581-1599

Seifollahi-Aghmiuni S, Haddad OB, Omid MH, Mariño MA (2011) March. Long-term efficiency of water networks with demand uncertainty. In Proceedings of the Institution of Civil Engineers-Water Management 164(3): 147-159.

Shafiqul Islam M, Sadiq R, Rodriguez MJ, Najjaran H, Hoorfar M (2014) Reliability assessment for water supply systems under uncertainties. Journal of Water Resources Planning and Management 140(4): 468-479

Sharp WW, Walski TM (1988) Predicting internal roughness in water mains. Journal-American Water Works Association 80(11): 34-40

Shibu A, Reddy MJ (2011) Uncertainty analysis of water distribution networks by fuzzy-cross entropy approach. World Acad. Sci., Eng. Technol. 59: 724-731

Shibu A, Reddy MJ (2012) Least cost design of water distribution network under demand uncertainty by fuzzy -cross entropy method. J. Environ. Res. Dev. 6 (3A): 853-862

Shirzad A, Tabesh M (2016) New indices for reliability assessment of water distribution networks. Journal of Water Supply: Research and Technology-AQUA 65(5): 384-395

Spiliotis M, Tsakiris G (2012) Water distribution network analysis under fuzzy demands. Civ. Eng. Environ. Syst. 29(2): 107-122

Taebi A, Chamani MR (2005) Urban water distribution networks. publication center of Isfahan Industrial University, Isfahan (In Persian)

Vamvakeridou-Lyroudia LS, Walters GA, Savic DA (2005) Fuzzy multiobjective optimization of water distribution networks. Journal of water resources planning and management, 131(6): $467-476$ 
Wang Q, Guidolin M, Savic D, Kapelan Z (2015) Two-objective design of benchmark problems of a water distribution system via MOEAs: Towards the best-known approximation of the true Pareto front. Journal of Water Resources Planning and Management 141(3): 04014060

Xu C, Goulter IC (1999) Optimal design of water distribution networks using fuzzy optimization. Civ. Eng. Environ. Syst. 16(4): 243-266 